\title{
PRESUNCIÓN DE CULPA. \\ LA DEDUCCIÓN DE NEGLIGENCIA EN LA RESPONSABILIDAD PATRIMONIAL DE LA ADMINISTRACIÓN
}

\author{
Felio José Bauzá Martorell \\ Universidad de las Islas Baleares
}

\begin{abstract}
RESUMEN
Pese a su carácter aparentemente consolidado, la responsabilidad patrimonial sigue estando huérfana de una teoría general, habiéndose construido a golpe de sentencia y de dictamen consultivo. En la dialéctica acerca de la calificación de la responsabilidad como objetiva o subjetiva, la presunción de culpa ha pasado desapercibida durante décadas en nuestro país, pese a encontrarse presente y haberse admitido bajo la forma de la responsabilidad objetiva, con la que en ocasiones se ha confundido.

En las páginas que siguen se analiza la deducción de negligencia, su génesis en el Common law, y su importación a España, primero en la Sala de lo Civil del Tribunal Supremo, y posteriormente a la Sala de lo ContenciosoAdministrativo.
\end{abstract}

Palabras clave: responsabilidad patrimonial; presunción de culpa; prueba de presunciones; responsabilidad sanitaria.

\begin{abstract}
Despite its seemingly consolidated basis, the liability remains orphan of a general theory, having been built to blow judgment and advisory opinion. In the dialectic on the score responsibility as objective or subjective, the presumption of guilt has gone unnoticed for decades in our country, despite being present and have been admitted in the form of objective responsibility, which at times has confused.

In the following pages deduction of neglect, its genesis in the common law, and its importation to Spain, first in the Civil Chamber of the Supreme Court, and then to the Chamber for Contentious Administrative analyzed.
\end{abstract}

Keywords: liability; presumption of guilt; test assumptions; health responsabilty. 


\section{SUMARIO}

I. Planteamiento: 1. Estado regulador y culpabilidad. 2. Responsabilidad civil y culpa: A) La teoría de la culpa: se califica como objetiva una responsabilidad subjetiva en la que se presume la culpa.-II. ONUS PROBANDI Y PRUEBA DE PRESUNCIONES: 1. De la rigidez del principio de aportación a la distribución dinámica de la carga de la prueba. 2. Disponibilidad y facilidad probatorias. 3. Prueba de presunciones: A) Prueba de los hechos. B) Máximas de experiencia y sana crítica. C) Límites a la presunción.-III. DistincIONES DE LA PRESUNCIÓN DE CULPA: 1. Responsabilidad objetiva o por riesgo. 2. Culpa in vigilando. 3. Inversión de la carga de la prueba.-IV. TEORÍAS SOBRE LA PRESUNCIÓN DE CULPA: 1. Res ipsa loquitur: A) Concepto y naturaleza. B) Límites. 2. Faute virtuelle. 3. Prima facie y Anscheinsbeweis. 4. Daño desproporcionado.-V. LA PRESUNCIÓN DE CULPA EN ESPAÑA: 1. El deber jurídico de soportar un riesgo. 2. Caídas en la vía pública. 3. Lesiones sufridas en establecimientos públicos. 4. Suicidio en establecimientos públicos. 5. La responsabilidad en la edificación. 6. La responsabilidad en el deporte. 7. Lesiones causadas por las fuerzas y cuerpos de seguridad. 8. Daños causados por la ejecución de obras públicas.-VI. LA PRESUNCIÓN DE CULPA EN LA RESPONSABILIDAD MÉDICA: 1. Responsabilidad por culpa y lex artis como estándar objetivo de diligencia: A) Daño desproporcionado y lex artis ad hoc. B) Daño desproporcionado y presunción de culpa. 2. Alcance y límites de la presunción de culpa en el daño desproporcionado: A) Infecciones nosocomiales. B) Transfusiones. C) Retrasos y errores de diagnóstico. La pérdida de oportunidad terapéutica. D) Consentimiento informado.-VII. CONCLUSIONES Y RECOMENDACIONES DE LEGE FERENDA.

\section{Planteamiento}

\section{Estado regulador y culpabilidad}

El Estado tradicional prestador de servicios ha cedido en favor de una Administración preponderantemente reguladora, que destina principalmente sus actuaciones a dos ejes: la potestad reglamentaria y el procedimiento sancionador. En ambos sentidos el ciudadano es el agente subjetivo sobre el que se despliega toda la vis publica de la Administración, asumiendo imperio legis una responsabilidad en muchos casos absolutamente desconocida ${ }^{1}$.

En este contexto del Estado regulador es como los diarios oficiales se inundan de normas, ordenanzas y reglamentaciones técnicas que, afectando a sectores específicos de actividad (calidad, medio ambiente, edificación, alimentación, deporte...) y bajo cualquier denominación y origen (el caso del soft law resulta paradigmático), establecen requisitos y exigen responsabilidades a los ciudadanos.

1 Vid. la carta cuarta, «Sobre la ley y sus sicofantes», en A. Nieto y T. R. FERnández (1998), El Derecho y el revés. Diálogo epistolar sobre leyes, abogados y jueces, Barcelona: Ariel, págs. 61 y ss. 
En consecuencia la Administración, a la hora de regular, hace descansar la responsabilidad sobre el elemento de la culpabilidad, siendo así que en ocasiones resulta inviable una determinación absoluta de la misma, haciendo acopio de la responsabilidad objetiva y —allí donde es subjetiva- una culpa in vigilando, una culpa levísima y hasta una presunción de culpa.

\section{Responsabilidad civil y culpa}

A) La teoría de la culpa: se califica como objetiva una responsabilidad subjetiva en la que se presume la culpa

El principal problema del instituto de la responsabilidad es que a día de hoy todavía no hemos sido capaces de crear una teoría general sobre la misma, sino que - al decir de GARCíA DE ENTERRÍA- la responsabilidad se ha ido construyendo sobre la base de decisiones judiciales, lo que equivale a decir a partir de la casuística ${ }^{2}$. Esta nota definitoria no sería tan grave si no afectara a la seguridad jurídica (REBOLLO PUIG) ${ }^{3}$.

Por razones obvias esta falta de una teoría general permite corrientes jurisprudenciales sujetas a evolución y cambio, al tiempo que avoca irremediablemente a una inseguridad jurídica galopante. No en vano NIETO califica con total acierto al instituto de la responsabilidad administrativa como «un juego de azar o una adivinanza» 4 .

En el fondo de esta cuestión subyace, según GARCÍA DE ENTERRÍA, la doctrina de la culpa como fundamento de la responsabilidad civil, que impera hasta hoy mismo, y que supone la dificultad de atribuir a la Administración una culpa propia, en lugar de atribuirla al agente que obra en su nombre.

La presunción de culpa constituye una novedad en un ordenamiento como el español, de corte continental, en el que procesalmente la regla general consiste en el principio de aportación, de suerte que la deducción de negligencia solo puede aplicarse por el operador jurídico con una interpretación restrictiva.

\footnotetext{
2 E. García De Enterría (2006), Los principios de la nueva Ley de Expropiación Forzosa, Thomson-Civitas, pág. 166.

3 M. Rebollo Puig (2004), «Sobre la reforma del régimen de responsabilidad patrimonial de la Administración», en F. SAINz MoReno (dir.), Estudios para la reforma de la Administración Pública, Madrid: Ministerio de Administraciones Públicas-Instituto Nacional de Administración Pública, págs. 215 y ss.

4 A. Nieto (1986), "La relación de causalidad en la responsabilidad administrativa», en Revista Española de Derecho Administrativo, 51, pág. 90.
} 


\section{ONUS PROBANDI Y PRUEBA DE PRESUNCIONES}

1. De la rigidez del principio de aportación a la distribución dinámica de la carga de la prueba

La presunción de culpabilidad se ha ido incorporando a la práctica administrativa y forense a medida que se ha ido atemperando el rigor de la norma distributiva de la carga de la prueba.

En aplicación de la remisión normativa establecida en el artículo 60.4 de la vigente Ley 29/1998, de 13 de julio, rige en el proceso contencioso-administrativo el principio general (art. 217 LECiv), que atribuye la carga de la prueba a aquel que sostiene el hecho, en cuya virtud cada parte soporta la carga de probar los datos que, no siendo notorios ni negativos y teniéndose por controvertidos, constituyen el supuesto de hecho de la norma cuyas consecuencias jurídicas invoca a su favor.

En este sentido debe advertirse que - al margen de su calificación jurídica - la carga de la prueba se concibe como una regla de juicio, dirigida al órgano administrativo o jurisdiccional, y que le permite resolver la controversia en aquellos supuestos en los que la actividad probatoria desarrollada en el procedimiento o proceso, respectivamente, no ha sido suficiente para convencerle sobre la certeza de los hechos introducidos ${ }^{5}$. Su objeto consiste en determinar para quién han de producirse las consecuencias desfavorables en el caso de que un hecho no haya resultado probado $^{6}$. Su fundamento último radica en la prohibición del non liquet que pesa sobre todo juzgador ${ }^{7}$.

La LECiv vigente no solo deroga el art. 1214 CC, sino que introduce una cláusula de cierre en su art. 217 —que lleva por epígrafe «carga de la prueba»— no permitiendo, sino obligando al tribunal a tener presente la disponibilidad y facilidad probatorias a cada una de las partes en el litigio.

La interpretación que opera el legislador consiste en constatar una asimetría y un desequilibrio entre autor y víctima del daño, de manera que la casuística da lugar a que el beneficiario de una prueba -la víctima- no se encuentre en condiciones de aportarla porque la misma se halla en el ámbito de influencia del autor material del daño ${ }^{8}$. Y en este

5 L. Muñoz Sabaté (1967), Técnica probatoria, Barcelona: Praxis, pág. 146.

6 J. E. Corbal Fernández (1993), "La adquisición procesal y la carga de la prueba», en AA.VV., La prueba en el proceso civil, Cuadernos de Derecho Judicial, XXXIV, Madrid: Consejo General del Poder Judicial, pág. 173.

7 M. Serra Domínguez (1981), "Comentario al artículo 1214 del Código Civil», en M. AlbaLAdejo (dir.), Comentarios al Código Civil y Compilaciones Forales, Madrid: Edersa.

8 E. Llamas Pомвo (2000), «Responsabilidad médica, culpa y carga de la prueba», en J. A. Moreno Martínez (dir.), Perfiles de la responsabilidad civil en el nuevo milenio, Madrid: Dy- 
fundamento descansa la tutela judicial efectiva, porque — de no exigirse la aportación de la prueba al demandado- el demandante tendría vedada la posibilidad de resarcirse del daño.

La doctrina procesalista coincide en que la alteración de las reglas de la carga de la prueba se ampara en los criterios de normalidad y de facilidad. En el primer caso, la normalidad se traduce en que aquellos hechos que son habituales y normales pueden presumirse. Por razones obvias, y como se analiza más adelante, esta normalidad no puede ser tímida, sino que la jurisprudencia exige que sea cualificada; pero en cualquier caso el principio de normalidad constituye una proyección de las máximas de experiencia y se funda en la idea de que resulta obvio que si algo se repite o sucede con frecuencia, se convierte en normal, por lo que el acaecimiento contrario se considera anormal y debe probarse ${ }^{9}$.

\section{Disponibilidad y facilidad probatorias}

La LECiv introduce en el art. 217.7 dos criterios correctores a las reglas tradicionales de valoración de la prueba, admitiendo que no siempre quien alega unos hechos, puede aportarlos al proceso ${ }^{10}$.

La disponibilidad y la facilidad probatorias se hallan íntimamente relacionadas, si bien se distinguen en que en la primera la prueba se halla en el ámbito de influencia de una de las partes (se entiende la demandada), mientras que en la segunda a una de las partes le resulta aportarla menos gravosa o puede hacerlo con mayor facilidad.

En ambos casos la disponibilidad y facilidad probatorias participan del deber constitucional de colaborar con la justicia que contempla el art. 118 $\mathrm{CE}$, que se traduce en el deber de traer al proceso una prueba aun siendo contraria a sus propios intereses, todo ello dirigido al esclarecimiento de los hechos. Y ello sin olvidar el principio constitucional de justicia a que estas reglas sirven, tratando de evitar que la víctima de un daño sea doblemente víctima: del daño y de la imposibilidad de probar su causa ${ }^{11}$.

kinson, pág. 305. A. Domínguez Luelmo (2003), Derecho sanitario y responsabilidad médica, Valladolid: Lex Nova, pág. 66.

9 J. E. Corbal Fernández (1993), "La adquisición procesal y la carga de la prueba», en AA.VV., La prueba en el proceso civil. Cuadernos de Derecho Judicial, XXXIV, Madrid: Consejo General del Poder Judicial, págs. 184 y 205.

10 Montero Aroca señala que los criterios de disponibilidad y facilidad probatorias no son una excepción a los apartados 2 y 3 del art. 217 LECiv, sino como un complemento de los mismos. J. Montero Aroca (dir.) (2013), Derecho Jurisdiccional II. Proceso Civil. $22^{\mathrm{a}}$ ed., Valencia: Tirant lo Blanc, pág. 231.

11 A. Luna Yerga (2004), La prueba de la responsabilidad civil médico-sanitaria. Culpa y causalidad. Prólogo de Pablo Salvador Coderch, Madrid: Thomson Civitas, pág. 27. 
En nuestro ordenamiento jurídico y pese a las reticencias de algún sector de la doctrina procesalista ${ }^{12}$, la jurisprudencia del Tribunal Supremo, con base en la Ley de Enjuiciamiento Civil, viene admitiendo la facilidad y disponibilidad probatoria en las reclamaciones de responsabilidad patrimonial ${ }^{13}$.

\section{Prueba de presunciones}

\section{A) Prueba de los hechos}

La presunción de culpabilidad se halla en el seno de las presunciones judiciales que regula el art. 386 LECiv. En este sentido, a pesar de que el art. 217 LECiv contemple en una norma de rango legal la interpretación de que puede hacer uso el juez, no por ello esta es una presunción legal del art. 385 LECiv. Por el contrario, el art. 217 obliga al juez a realizar una ponderación y a presumir, a partir de un hecho, otro distinto directamente relacionado. En síntesis la presunción conduce al juzgador a tener un hecho por cierto, aunque no se haya probado, a partir de la certeza indubitada de otro hecho con el que guarda relación lógica y probable.

La presunción no opera de forma automática como las presunciones legales ${ }^{14}$, sino que exige un razonamiento amparado en las reglas de la sana crítica y las máximas de experiencia. Precisamente, y como se expondrá con mayor detenimiento, por este motivo no es posible afirmar que se invierta la carga de la prueba o que la responsabilidad se torne objetiva. Antes al contrario, siendo subjetiva la responsabilidad

12 TAPIA FernÁndez considera que el recurso a este mecanismo conculca el principio según el cual ha de recaer sobre las partes la carga de la proposición de las pruebas de que intenten valerse en el proceso. I. TAPIA FERnÁNDEZ (2001), «Comentario al artículo 217 LEC», en F. CoRdón Moreno, T. Armenta Deu, J. J. Muerza Esparza e I. Tapia Fernández (coords.), Comentarios a la Ley de Enjuiciamiento Civil, vol. II, Cizur Menor: Aranzadi, pág. 785.

13 Así, debe citarse por su claridad de planteamiento doctrinal la Sentencia del Tribunal Supremo, Sala Tercera, de lo Contencioso-Administrativo, de 23 de febrero de 2009 (rec. 7840/2004), en la que - refiriéndose a un caso de retraso en el diagnóstico médico con el consiguiente daño en la salud del paciente — señala que «esta prueba puede ser [...] la de presunciones, admitida actualmente en nuestro derecho por el artículo 386 de la Ley 1/2000, de 7 de enero, de Enjuiciamiento Civil (BOE de 8 de enero), de modo que si, a partir de circunstancias especiales debidamente probadas y acreditadas, se obtiene, mediante un enlace preciso y directo conforme a las reglas del criterio humano, que el daño que sufre el paciente resulta desproporcionado y desmedido con el mal que padecía y que provocó la intervención médica, cabrá presumir que ha mediado una indebida aplicación de la lex artis [véanse las sentencias de la Sala Primera del Tribunal Supremo de 17 de mayo de 2002 (casación 3475/96, FJ 6º y 26 de marzo de 2004 (casación 1458/98, FJ 2º)».

14 Sobre un análisis exhaustivo de las presunciones legales en derecho administrativo, vid. T. CANo CAmpos (2008), Presunciones y valoración legal de la prueba en el derecho administrativo sancionador, Cizur Menor: Thomson-Civitas. 
y en consecuencia predicable exclusivamente en caso de culpabilidad, se induce al demandado a presentar prueba en contra, pues el hecho de no presentarla puede considerarse la base de una presunción judicial ${ }^{15}$.

Lo relevante en materia de deducción de negligencia en sede de responsabilidad patrimonial consiste en que la presunción se proyecta sobre los hechos. No obstante lo anterior, no es posible confundir la técnica de la presunción con la doctrina procesal de los facta concludentia, de suerte que - pese a tratarse, como decimos, de hechos- la presunción exige la ponderación del juzgador según la sana crítica, mientras que en los facta concludentia deviene innecesario cualquier juicio de razonabili$\operatorname{dad}^{16}$. Como tampoco puede confundirse la prueba de presunciones con las meras deducciones o conjeturas que efectúa el juzgador con ocasión de la valoración de la prueba, sino que más bien se tratan de deducciones o inferencias lógicas, basadas en la experiencia, que posibilitan juicios hipotéticos, obtenidos de hechos o circunstancias concluyentes, pero que en ningún modo impiden alterar las reglas de la prueba del art. 217 LECiv.

Otra cosa es que los hechos que acaecen en una reclamación de responsabilidad patrimonial, pese a su carácter fáctico, tengan indudables consecuencias jurídicas. Los hechos por sí solos son reveladores de una causalidad y una autoría, de ahí que de los mismos deriven consecuencias indemnizatorias. VINOGRADOFF, en este sentido, pasa de los facts and acts in Law a los facts in Law para atribuir a determinados hechos una eficacia jurídica ${ }^{17}$.

\section{B) Máximas de experiencia y sana crítica}

Estas reglas a que nos referimos, y que permiten elaborar el razonamiento, consisten en criterios o juicios de carácter abstracto o general, de los que se vale el juzgador a raíz de su experiencia y del conocimiento de los hechos para interpretar lo sucedido y determinar la verdad. Estas reglas no tienen carácter jurídico, sino científico, artístico, técnico... si bien permiten la aplicación de normas jurídicas.

15 A. LunA Yerga (2003), "Olvido de una gasa durante una intervención quirúrgica», InDret, Working Paper 141, Barcelona, pág. 5.

16 L. Muñoz Sabaté (2001), Fundamentos de prueba judicial civil. LEC 1/2000, Barcelona: Bosch, pág. 414.

17 «As soon as this has been stablished, we have to deal with facts-in-law. The fact of accidental death in consequence of an unpremeditated assault, and the fact that the slayer was intoxicated, lead to legal consequences: a sentence will be pronounced by the Court, which will formulate these consequences in the particular case according to certain legal rules provided with a sanction», P. Vinogradoff (2006), Common-sense in Law, New Jersey: The Lawbook Exchange Ltd. Clark, pág. 89. 
Las máximas de experiencia y la sana crítica permiten al juez obtener una certeza que tiene un innegable componente subjetivo, si bien debe fundamentar y justificar cómo llega a esa convicción.

En materia de presunción de prueba, las máximas de experiencia permiten conocer un hecho, valorarlo e inferir el nexo o vínculo entre el hecho base y el presumido. La experiencia de la vida ya ha probado un mismo hecho en una generalidad de casos similares, de ahí que el razonamiento del juzgador tenga una fundamentación empírica ${ }^{18}$.

\section{C) Límites a la presunción}

La presunción de negligencia en cuanto método probatorio se halla sujeta a los mismos límites que cualquier valoración de prueba, de manera que habrá que aplicar la prohibición de este método en caso de que lesione determinados valores preferentes para el ordenamiento jurídico (art. 11.1 LOPJ).

De forma particular a la prueba de presunciones, la interpretación deductiva no puede llevarse a cabo de cualquier manera, sino que se encuentra sometida a unas reglas internas, que se refieren al propio razonamiento presuntivo y a la forma en que se produce (art. 386.1). En este sentido no puede pasar inadvertido que la conexión entre la lesión y la culpa presumida debe tener una consistencia interna (ORTELLS se refiere a una probabilidad en grado cualificado), extremo que nos conduce invariablemente a la motivación.

Lo contrario supone el peligro de un excesivo reduccionismo que puede minimizar el elemento de la culpa, desnaturalizando esta materia de un ámbito como la responsabilidad civil, en el que resulta clave ${ }^{19}$.

\section{Distinciones DE LA PRESUNCIÓN DE CULPA}

La presunción de culpa no supone una presunción judicial del daño ni de su desproporción; como tampoco puede identificarse con la responsabilidad objetiva - en la que el resultado convierta en estéril cualquier apreciación subjetiva en la generación del daño- ni la inversión de la carga de la prueba.

18 M. YzQuierdo Tolsada (1989), La responsabilidad civil del profesional liberal. Teoría general, Madrid: Reus, pág. 309.

19 Fundamento de derecho tercero in fine del voto particular del magistrado Excmo. Sr. Francisco Marín Castán a la Sentencia del Tribunal Supremo, Sala Primera, de lo Civil, de 31 de enero de 2003 (rec. 1807/1997). 
Por el contrario, en la presunción de culpa, con base en la facilidad y disponibilidad probatorias, se traslada al autor del daño la exigencia de que explique razonablemente su diligencia, de manera que será la ausencia de esta explicación razonable la que haga surgir en su contra una presunción de causalidad y, por extensión, de negligencia.

\section{Responsabilidad objetiva o por riesgo}

No son infrecuentes los casos en que doctrina y jurisprudencia, tanto en derecho nacional como comparado, confunden la presunción de culpa con la responsabilidad objetiva, cuando en realidad ambas cuestiones resultan frontalmente opuestas.

En efecto, la responsabilidad objetiva es una responsabilidad sin culpa, que opera automáticamente por la concurrencia de hechos previstos en una norma. Tal es el caso de los supuestos contemplados en el art. 1903 CC, en los que el responsable civil lo es de forma objetiva, esto es, al margen del elemento de la culpabilidad, sin mediar dolo ni negligencia. Por el contrario, para traer a colación la presunción de culpa no podemos hallarnos en sede de responsabilidad objetiva, puesto que en ese caso carece de sentido presumir culpa cuando la misma sencillamente no existe.

\section{Culpa in vigilando}

La culpa in vigiliando o in omittendo no es más que una modalidad de la presunción de culpa, que en cualquier caso se distingue de esta última en que la causa del daño sí se conoce. Sobre esta modalidad de culpa opera una presunción, si bien no exactamente para deducir un hecho, sino para interpretar directamente la responsabilidad.

En ocasiones la jurisprudencia califica directamente la culpa in vigilando como una presunción de culpa $\operatorname{propia}^{20}$. Debe citarse en este punto, tanto por su interés en la distinción entre presunción de culpa y culpa in vigilando como por el propio de la delimitación entre la responsabilidad de los facultativos y del sistema público de salud, la Sentencia

20 Así, la Audiencia Provincial de Guipúzcoa en Sentencias de 11 y 24 de enero de 2001 en sus FJ 16 y 18, respectivamente, tiene declarado que «la obligación de reparar el daño causado por culpa es exigible no solo por los actos u omisiones propios, sino también por los de aquellas personas por los que se debe responder teniendo como fundamento esta responsabilidad en una presunción de culpa propia, in eligendo o in vigilando, o incluso en la creación de un riesgo». 
del Tribunal Supremo, Sala Primera, de lo Civil, de 26 de septiembre de 1997 (rec. 2503/1993). A la reclamante se le extirpó un mioma en un ovario y en el transcurso de la operación se desprendió un tornillo de $4 \times 3$ milímetros de un retractor. Tres años más tarde se descubre el tornillo y como consecuencia se le tuvo que practicar una histerectomía con doble anexectomía. Tanto en instancia como en casación se absolvió a los médicos y se condenó al INSALUD por no haber conservado el material quirúrgico. Es decir, se probó que los facultativos habían actuado conforme a la lex artis, y que en cambio había sido el centro hospitalario el que no había sido diligente en la conservación del material ${ }^{21}$.

\section{Inversión de la carga de la prueba}

La doctrina procesalista distingue la inversión de la carga de la prueba en sentido estricto, es decir, un trasvase de los hechos a probar de una parte a la otra, de aquella inversión en sentido amplio, comprensiva de simples relevaciones o exoneraciones, y que se califican no como inversión, sino modificación de la carga de la prueba ${ }^{22}$.

En efecto, las distintas teorías que fundamentan la presunción de culpa adolecen de un grado de complejidad mayor que el de una mera inversión de la carga de la prueba. Esta última institución se aplica, a tenor del art. 217 LECiv, en materias de especial sensibilidad social y, por ende, política (la discriminación por razón de sexo, apdo. 5) o de especial dificultad probatoria (competencia desleal y publicidad ilícita, apdo. 4).

Como puede apreciarse, el automatismo preside la inversión de la carga de la prueba, que opera ope legis por razón de la materia. En cambio, la deducción de negligencia se ampara no en la inversión de la carga de la prueba, sino en la facilidad y disponibilidad probatorias (apdo. 7), extremo que exige un grado de ponderación por parte del juzgador ${ }^{23}$. En

21 «[... es llano, que, pese a que en el F.J. $4^{\circ}$ se exime de responsabilidad a los facultativos intervinientes, por haberse ajustado su actuación a la "Lex Artis ad Hoc", no obstante, en el F.J. $5^{\circ}$, la Sala aprecia como una auténtica "quaestio facti" que no es posible rectificar (tal y como verifica el motivo del recurso) cuál ha sido la causa por la cual se le imputa la responsabilidad al ente recurrente, esto es, porque sin perjuicio de aquella diligencia de los facultativos, que se constata, por lo que respecta al material preciso para la intervención, que el mismo no había sido conservado con la exquisita atención o diligencia; cometido este que incumbe al ente recurrente, sobre todo, si según ese F.J. $5^{\circ}$, el material había llegado al final de su vida, puesto que "se ha puesto de manifiesto su fatiga al desprenderse..."; aspecto este coadyuvante para determinar que al margen de aquella diligencia profesional, estas circunstancias implican una especie de dejación o negligencia por parte del Insalud causante de la responsabilidad acoplada».

22 V. CoRtés Domínguez (1972), "Algunos aspectos de la inversión de la carga de la prueba», Revista de Derecho Procesal Iberoamericana, 2-3, pág. 598.

${ }_{23}$ N. Cabezudo Rodríguez (1998), «La regla de juicio de la carga de la prueba y su inversión 
la presunción de culpa no se invierte la carga de la prueba, sino que se infiere la negligencia a partir de unos hechos probados.

\section{TEORÍAS SOBRE LA PRESUNCIÓN DE CULPA}

No son pocas las teorías que explican la presunción de culpa en los distintos ordenamientos. Ya sea el res ipsa loquitur del Common law, la faute virtuelle de la jurisprudencia francesa, la prima facie italiana, la Anscheinsbeweis alemana o la teoría del daño desproporcionado en nuestro país, la deducción de la negligencia, con sus matices, no es infrecuente en derecho comparado y se va imponiendo cada vez más.

La presunción de culpa nació en el Common Law a través de la doctrina del res ipsa loquitur, y pasó al derecho continental a través de la doctrina francesa de la faute virtuelle. En España no se recibió hasta 1996, cuando la Sala Primera del Tribunal Supremo desarrolló la teoría del daño desproporcionado.

La finalidad de estas teorías es idéntica: presumir la culpa y el nexo causal a través de la evidencia (res ipsa loquitur), la anormalidad del resultado (culpa virtual) o de máximas de experiencia (prima facie), que encierran la misma idea de que, según las reglas de la lógica o de la experiencia humana, la conducta del autor del daño tuvo que ser negligente para causar ese resultado ${ }^{24}$.

\section{Res ipsa loquitur}

\section{A) Concepto y naturaleza}

Esta doctrina hunde sus raíces más remotas en la expresión acuñada por Cicerón en su discurso Pro Milone en el año 52 a. C. (res loquitur ipsa, iudices, quae Semper valet plurimum), en un juicio penal para defender a un acusado de asesinato ${ }^{25}$.

en el proceso civil», en Revista del Poder Judicial, 52, 4º trim., pág. 259.

${ }_{24}$ M. M. SÁnchez García (2013), "El daño desproporcionado», en Revista CESCO de Derecho de Consumo, 8, pág. 250.

25 Marco Tulio Cicerón defiende ante el Senado a su amigo pretor y aspirante a cónsul Titus Annius Milo, acusado de asesinar al tribuno y aspirante a pretor Publius Clodius Pulcher en plena Via Appia en el seno de una reyerta entre esclavos de ambos. Milo estaba casado con una hija del emperador Sila y en consecuencia gozaba de la simpatía de Pompeyo, si bien y pese a la laudatio de Cicerón, Milo fue condenado por el asesinato de Clodio. A. CASAmento (2006), «Spettacolo della giustizia, spettacolo della parola: il caso della pro Milone», en G. Petrone y A. Casamento (eds.), Lo spettacolo della giustizia. Le orazioni di Cicerone, Palermo, págs. 181-198. 
Prácticamente dos mil años más tarde se hace acopio de esta expresión en el Common Law (the thing speaks for itself) para construir la teoría de la deducción de negligencia en un caso -Byrne vs. Boadle-de la Court of Exchequer (1863), en el que el demandante fue víctima de la caída de un barril de harina desde un segundo piso. El demandante, a quien correspondía la carga de la prueba, no pudo explicar cómo ocurrieron los hechos, y por ello el ponente Barón Polock tuvo que interpretar que el barril se encontraba bajo el control del demandado, y que por consiguiente solo podía existir negligencia en la custodia del mismo ${ }^{26}$.

En el origen de la teoría res ipsa loquitur radica el problema de la dificultad probatoria de un daño. La clave para distinguir el res ipsa de otras doctrinas semejantes consiste en que existe un daño, que nadie discute, si bien se desconoce cómo se ha producido. El res ipsa en consecuencia afecta al onus probandi, pero su foco se dirige no tanto a la relación de causalidad entre el daño y la acción cuanto a esta última. La jurisprudencia, tanto en derecho comparado como en nuestro país, trae a colación esta teoría cuando no es posible determinar cómo se ha producido el daño, esto es, cuál es la causa que puede haberlo provocado.

Dos años más tarde, en 1865, vuelve a enjuiciarse un caso muy similar al anterior: el demandante caminaba junto a un almacén y en esta ocasión son sacos de azúcar los que caen sobre su cabeza. Este fue el asunto Scott vs. London and St. Katherine Docks, en el que el Tribunal estableció que «cuando el objeto que causa el daño está bajo el control del demandante o sus empleados, y se produce un accidente que no suele ocurrir en el curso normal de los acontecimientos si quienes están encargados de controlar la situación no actúan con diligencia, a falta de una explicación por parte del demandante, constituye prueba razonable de que el accidente se produjo por falta de negligencia» ${ }^{27}$.

Vid. también en la doctrina española M. Alonso PéRez (2000), «La relación médico-enfermo, presupuesto de responsabilidad civil (en torno a la lex artis)», en J. A. Moreno Martínez (dir.), Perfiles de la responsabilidad civil en el nuevo milenio, Madrid: Dykinson, pág. 49.

26 «Somos de la opinión que la regla debe ser dictar un veredicto a favor del demandante. [...] es cierto cuando se dice que existen muchos accidentes de los que no puede derivarse una presunción de negligencia, pero creo que sería un error establecer una regla según la cual no puede surgir nunca una presunción de negligencia del hecho de un accidente. Supongamos en este caso que el barril rodó fuera del almacén y cayó sobre el demandante. ¿Cómo podría demostrarse con certeza cuál fue la causa de lo ocurrido? Es obligación de la persona que guarda barriles en un almacén tomar cuidado para que no rueden hacia fuera, y creo que tal caso debería, fuera de toda duda, establecer prima facie evidencia de negligencia. Un barril no se puede rodar fuera de un almacén sin alguna negligencia y decir que el demandante que fue herido es el que debe traer testigos me parece descabellado», Byrne v. Boadle [1863] 159 Eng. Rep. 299.

27 Scott v. London and St. Katherine Docks Co [1865] 3 H\&C 596. 
La aplicación de la regla res ipsa loquitur se consolida en el asunto Mahon v. Osborne (1939), en el que se perfilan los requisitos para su aplicación. En este caso durante una intervención quirúrgica los facultativos olvidaron una esponja en el interior del paciente, que no fue descubierta hasta dos meses después, provocando una infección que causó el fallecimiento del paciente ${ }^{28}$.

En este sentido resulta definitorio el asunto conocido por la Corte Suprema de California Ybarra vs. Spangard (1944), en la que un paciente despierta de la anestesia de una intervención quirúrgica con fuertes dolores musculares en un hombro, que solo pueden haberse producido - al decir de un dictamen pericial- porque algún médico o enfermera hayan ejercido presión sobre el mismo durante la operación. El Sr. Ybarra demandó a todo el equipo médico, que se defendió señalando que el demandante no había aportado prueba alguna, extremo que la Corte apreció, si bien admitió que la parte que podía aportar las pruebas de cómo había discurrido la operación era el equipo médico y no el paciente anestesiado, de manera que desarrolló la evidencia de que había existido negligencia.

La doctrina del res ipsa trata de imponer un resultado de justicia material por encima de las reglas procesales de la carga de la prueba. Esta teoría se fundamenta en el control de la actividad, de suerte que la casuística demuestra que no siempre las partes se encuentran en igualdad de condiciones para afrontar la carga probatoria. Por el contrario existen supuestos en que el agente eventualmente productor del daño se encuentra en mejor aptitud para conocer exactamente la acción que se produjo y si la misma fue la causa del daño. En esta tesitura y con los límites que a continuación se exponen, es por lo que el juez o tribunal puede exigir al demandado, no por el capricho de invertir la carga de la prueba, sino -insistimos- porque tiene un conocimiento mayor de lo sucedido que la víctima, la aportación de pruebas al proceso. Esta es la lógica del res ipse, evitar que el demandado, que ya de por sí tiene un control de los hechos, pueda hacer dejadez, encogerse de hombros y esperar a que la reclamación se archive por falta de pruebas, porque no se olvide que la condena a indemnizar corre el riesgo de convertirse en el mayor incentivo para dejar de aportar pruebas al proceso ${ }^{29}$.

28 Mahon v. Osborne [1939] 2 KB 14.50.

${ }^{29}$ Más que justicia material, algunas sentencias se refieren a una cuestión de sentido común la aplicación del res ipse loquitur. Así, en el caso Barkway vs South Wales Transport Co. Ltd (1950), la Corte del Reino Unido determinó que «la máxima no es más que una simple regla de prueba que afecta al responsable. Se basa en el sentido común, y su propósito es hacer viable la justicia que debe hacerse cuando los hechos referidos a la causalidad y al cuidado ejercido por el demandado están fuera del conocimiento del demandante pero están o debe- 


\section{B) Límites}

Una presunción de culpabilidad tiene que ser forzosamente objeto de interpretación restrictiva, de manera que solo en los casos específicamente previstos podrá hacerse acopio de la misma en juzgados y tribunales.

No puede ocultarse el efecto perverso que una aplicación gratuita de esta teoría ocasionaría en el ordenamiento jurídico. En efecto, y al decir de BULLARD en la doctrina peruana, si la víctima de un determinado daño (por ejemplo el peatón en un accidente de tráfico o el asegurado en hurtos a vehículos) es conocedor que siempre y en todo caso se verá protegido por el derecho, irremediablemente abandonará cualquier precaución y el resultado no será otro que la proliferación de atropellos y hurtos $^{30}$. En consecuencia habrá que establecer filtros a la aplicación de esta teoría al objeto de evitar extralimitaciones consistentes en la inercia a desarrollar conductas que aumenten unos daños sencillamente por la convicción de que no se van a asumir.

\section{a. Ausencia de prueba directa}

Una primera limitación al uso del res ipsa loquitur consiste en que no puede existir certeza de los hechos que ocasionaron el daño. Al decir de la doctrina anglosajona, esta teoría "permite inferir negligencia bajo ciertas circunstancias en la ausencia de prueba directa ${ }^{31}$.

En caso contrario, si efectivamente los hechos son claros y no existe duda sobre los mismos, no podrá aplicarse esta teoría y habrá que acudir a las reglas generales de determinación de la culpabilidad. No en vano en el caso Barkway vs. South Wales Transport Co Ltd un autobús sufrió un accidente al reventar una rueda; un pasajero, el Sr. Barkway, demandó a la compañía sobre la regla del res ipsa loquitur, extremo que fue desestimado por conocerse exactamente la causa del accidente, de manera que el demandante tenía que haber probado que el siniestro de la rueda fue causado por la negligencia de la compañía ${ }^{32}$.

rían estar en conocimiento del demandado». Esta interpretación del sentido común también se expresó en el caso Lloyde vs. West Midlands Gas Board: «[...] exótica, pero conveniente frase para describir lo que no es en esencia más que una aproximación del sentido común [...] sobre la atribución de los efectos de las pruebas en determinadas circunstancias».

30 A. Bullard GonzÁlez (2005), «Cuando las cosas hablan: el res ipsa loquitur y la carga de la prueba en la responsabilidad civil», en Revista de Derecho de la Pontifica Universidad de Perú Themis, 50, pág. 222.

${ }^{31}$ M. A. Abramson y K. F. Dugan, Res Ipsa Loquitur and Medical Malpractice. Artículo doctrinal http://www.arbd.com/res-ipsa-loquitur-and-medical-malpractice.

32 «La doctrina depende de la ausencia de explicación, y, en consecuencia es un deber de los demandados, si es que desean protegerse, dar una explicación adecuada de la causa del ac- 


\section{b. Razonamiento judicial}

Sin perjuicio de lo que se dirá más adelante, a diferencia de la responsabilidad objetiva, en la res pisa no opera automáticamente la culpa del demandado, sino que el juez o magistrado debe inferir la misma a partir de la aportación de pruebas que le exija al proceso por su disponibilidad y facilidad probatorias. No se olvide que nos hallamos en sede de prueba de presunción, y en consecuencia resulta exigible una ponderación y un razonamiento que determine por qué y con base en qué criterios - dado que no existe prueba directa- se alcanza a inferir la culpa del demandado.

Tanto la jurisprudencia como la doctrina inciden mucho en este requisito. Así, en el caso Cowan vs. Tyrolean Ski Area, Inc., la Corte señaló que «la regla del res ipsa loquitur no requiere necesariamente que el demandante gane el juicio; es meramente una regla que identifica elementos de prueba indiciaria que son suficientes para llevar el caso ante un jurado y permitir al jurado dar un veredicto a favor del demandante». Por su parte, en sede doctrinal ABraham entiende que "cuando se cumplen los requisitos del res ipsa loquitur, en la mayoría de las jurisdicciones el efecto es que se permite al jurado, pero no se le requiere, encontrar que el demandado fue negligente» ${ }^{33}$.

En efecto, el razonamiento judicial resulta determinante para la presunción de culpa, que trae causa del convencimiento del juez a través de un juicio de probabilidades (balance of probabilities), esto es, la mayor probabilidad de que los hechos sucedieron mediando culpa del demandado $^{34}$.

c. Que el daño no haya podido ocurrir sin la existencia de negligencia de alguien

Este consiste en un requisito sine qua non para aplicar el res ipse loquitur. Ya sea en responsabilidad médica (dejar instrumental quirúrgico en el cuerpo del paciente) o en materia de colisión de aeronaves o

cidente, sin embargo, si los hechos son suficientemente conocidos, la pregunta deja de ser una referida a si los hechos hablan por sí mismos, y la solución debe encontrarse en determinar cuándo, sobre la base de los hechos establecidos, debe o no inferirse negligencia» (Barkway v. South Wales Transport Co [1950] 1 All ER 392, HL) (Lord Norman at 399), citada en D. GIESEN (1988), International Medical Malpractice Law. A Comparative Law Study of Civil Liability Arising from Medical Care, Boston, Tübingen: Mohr, pág. 515.

33 K. S. АвRAнам (1997), The Forms and Functions of Torts Law. New York: The Foundation Press, pág. 91.

34 C. Allen (2001), Practical Guide to Evidence, London: Cavendish Publishing Limited, págs. 128 y 129. 
ferrocarriles (dos trenes se encuentran en el mismo lugar en el mismo momento), resulta del todo punto evidente que existe negligencia de alguien $^{35}$. Otra cosa será identificar quién es el agente responsable, para lo cual la jurisprudencia acude a la teoría del control.

\section{d. Que el daño se encuentre en la esfera de control del demandado}

La negligencia va indisolublemente asociada al ámbito de cuidado que una persona debe tener: un médico tiene bajo su control el material quirúrgico, el tonelero del caso Byrne vs. Boadle tiene bajo su control el mantenimiento de los barriles...

En este punto se plantea la discusión del grado e intensidad de este control. Inicialmente en Estados Unidos el Restatement (Second) of $\operatorname{Torts}^{36}$ (\&328D, 1965) exigía que el control fuera exclusivo, si bien a partir de la tercera revisión (\&17) se suavizó para impedir que quedara sin indemnizar todo daño cuya causa negligente no estuviera bajo un absoluto control del causante. Todo lo contrario de lo sucedido en el Reino Unido, donde en el caso Gee vs. Metropolitan Ry (1873) se obligó a la compañía ferroviaria a indemnizar a un pasajero que cayó del tren porque se abrió una puerta y este extremo se encontraba bajo el control de la compañía, mientras que en el caso Easson vs. LNE Ry (1944), ante el mismo supuesto de caída por una puerta que se abre accidentalmente durante el viaje, la Corte determina que la puerta no se encuentra bajo el control exclusivo de la compañía y que cualquier pasajero - sobre el que la compañía no ejerce control— podría haberla abierto.

e. Que se hayan descartado otras posibles causas distintas de la negligencia del supuesto autor del daño

Ya sea por la contribución del perjudicado o por cualquier otra causa, no es posible inferir la culpa del demandado si su negligencia no es la única causa o la causa más posible del daño sufrido por la víctima. Este requisito recuerda a la ruptura del nexo causal sobre la base de la culpa del perjudicado.

Consecuente con lo anterior, en el caso Southeastern Aviation, Inc vs. Hurd (1962) se inadmitió esta regla porque el accidente pudo haber

${ }^{35}$ R. Fornas (2011), «Significado y alcance de la regla res ipsa loquitur. Supuestos de posible aplicación», en Derecho médico, 19 de junio.

${ }_{36}$ Los Restatements of Torts consisten en recopilaciones que elabora y publica desde 1979 la American Bar Association de criterios jurisprudenciales seguidos con carácter general en casos judiciales. 
ocurrido en el curso ordinario de las cosas, aunque todas las personas intervinientes en el proceso hubieran sido diligentes.

La regla del res ipse loquitur no puede convertirse en una solución universal e ilimitada. En el caso Hansen vs. James (1993) el demandante reclamó contra el dueño de una parcela en la que se situaba un poste de línea eléctrica. La víctima había chocado con su vehículo contra el poste, que derribó, entrando en contacto la línea con el coche. La Corte no admitió el res ipse porque el demandante había intervenido con su propia negligencia. Es decir, esta teoría no puede convertirse a una especie de equivalencia de las condiciones en la que tenga cabida cualquier causa posible.

\section{Faute virtuelle}

Sin perjuicio de los antecedentes del caso Jand'heur, cuyo fallo fue emitido por la Cour de Cassation el 13 de febrero de $1930^{37}$, la idea de la culpa virtual comienza a fraguarse en los años cuarenta del siglo xx. Por un lado la Sentencia de la Cour de Cassation de 5 de mayo de 1942 aplica este razonamiento a los daños recíprocos en materia de accidentes de circulación ${ }^{38}$. Por otra parte, STARCK ya defiende en 1947 las ficciones jurídicas que conecten el régimen de la Administración Pública a la causa de la justicia, "que es la única causa absoluta para el Derecho» ${ }^{39}$, motivo por el cual considera admisible la presunción de culpa si con ello se realiza un fin de justicia material.

En Francia la responsabilidad de la Administración ha ido derivando desde la responsabilidad por falta (faute de service) hasta la responsabilidad por riesgo, en aplicación de la doctrina de la igualdad — tan sensible en ese país - ante las cargas públicas ${ }^{40}$.

37 En la cual se estableció que la presunción de responsabilidad que implantaba la legislación francesa se establecía en contra de la persona que tenía bajo su guarda una cosa inanimada que haya causado un daño a otro y solo puede desvirtuarse mediante la prueba de una causa ajena, es decir, no se excluía el elemento culpa, pero no era la víctima la que tenía la carga de la prueba, sino era el guardián el que debía probar una causa ajena para poder exonerarse de la responsabilidad. Con esta sentencia se dio un paso importante en la discusión de la teoría de la culpa en contraposición a la de la responsabilidad objetiva.

38 Recueil Sirey (1942), págs. 125 y ss. Vid. H. Mazeaud (1942), «Nota a la Sent. Cass. Civ. de 5 de mayo de 1942», Recueil Sirey, págs. 125 y ss.

39 B. STARCK (1947), Essai d'une théorie générale de la responsabilité civile considérée en sa double fonction de garantie et de peine privée (prólogo de M. Maurice Picard), París: L. Rodstein, págs. 496-497.

${ }_{40}$ G. Teissier (1906), De la responsabilité de la puissance publique, París: Paul Dupont, parágrafos 147 y ss. L. Michoud (1906), La théorie de la personnalité morale et son aplication au droit français, Librairie Généralde de Droit et Jurisprudence, págs. 276 y ss. En España esta teoría ha sido criticada por GARCíA DE ENTERRÍA, para quien la igualdad ante las cargas públicas es un argumento de gran valor plástico, si bien no es válido como explicación jurídica, como 
Como tal, formalmente la presunción de culpa nace con la Sentencia de la Cour de Cassation de 28 de julio de $1960^{41}$, que acuña la teoría de la faute virtuell o culpa virtual, también conocida como presomtion de faute. En este caso una paciente, después de someterse a rayos $\mathrm{X}$, sufre una radio dermitis y se constata que las puertas protectoras del aparato se habían aflojado. El Tribunal se ampara en la obligación de garde o de vigilancia para afirmar la existencia de responsabilidad patrimonial ${ }^{42}$.

La culpa virtual ha tenido escaso predicamento en el país galo. Inicialmente acuñada en decisiones jurisprudenciales de la Cour de Cassation y del Conseil d'Etat, que la han confundido con la responsabilidad sin culpa, ha sido el legislador en 2002 quien la ha reducido a supuestos anecdóticos.

En este sentido la Corte administrativa de apelación de Lyon el 20 de diciembre de 1990 en el arret Gomez apunta a una responsabilidad sin culpa, si bien tres años más tarde el Consejo de Estado se refiere ya en el arret Bianchi de 9 de abril directamente a la presunción de responsabilidad, que lógicamente admite prueba en contrario. El razonamiento se formula a contrario, de manera que no se interpreta directamente que el demandado ha actuado con culpa, sino que no ha podido actuar sin ella.

La presunción de responsabilidad se consolida así a partir del arret Bonicci de 21 de mayo de 1996 de la Cour de cassation y del arret Hopital Joseph Imbert d'Arles del Consejo de Estado de 3 de noviembre de 1997, que la aplican a hospitales y clínicas en caso de infecciones nosocomiales contraídas en el interior de los establecimientos sanitarios. La culpa virtual se consolida así durante estos años con el arret de la Cour de cassation Belledone de 16 de junio de 1998, los tres arrets Staphylocoques dorés de 29 de junio de 1999 y de 23 de febrero de 2001.

Sin embargo, la aprobación y entrada en vigor de la Ley Kouchner 2002-303, de 4 de marzo de 2002, modifica sustancialmente este criterio jurisprudencial para arrinconarlo significativamente. Así, esta Ley, relativa a los derechos de los enfermos y a la calidad del sistema de sanidad, hace descansar el mecanismo de la responsabilidad sanitaria con carácter general sobre la existencia de culpa, y tan solo admite dos excepciones: la responsabilidad objetiva en caso de productos defectuosos, y la presunción de culpa para las enfermedades nosocomiales.

se demuestra con el paralelo del derecho civil, donde las indemnizaciones no se sustentan con fondos públicos. E. García de EnTERría (2006: 173).

41 JCP, 1960, II, 11787, anotada por SAVATIER.

42 P. LE Tourneau y L. Cadiet (1996), Droit de la responsabilité, París: Dalloz. 


\section{Prima facie y Anscheinsbeweis}

De manera convencional, en sede procesal la regla prima facie y el Anscheinsbeweis significa que existe suficiente evidencia para que un asunto sea admitido, aunque no prejuzga el fondo del asunto, a diferencia del res ipsa loquitur, que significa que los hechos son tan evidentes que una parte no necesita explicar más. Aplicada a la presunción judicial, la regla prima facie y Anscheinsbeweis permite al juzgador deducir un hecho incierto (la culpa) a partir de otro cierto (la anomalía que rompe el curso ordinario de las cosas).

Esta teoría se encuentra muy próxima a la exoneración de prueba, toda vez se fundamenta en la fijación de un hecho que tiene una explicación más que probable en otro hecho anterior. En este sentido la prima facie y la Anscheinsbeweis se dan en procesos causales anómalos y consiste en una prueba directa, que se satisface con la probabilidad. En cambio, la presunción en sentido estricto participa de una naturaleza indirecta, descansando sobre el hecho base o indiciario.

De origen anglosajón ${ }^{43}$, esta doctrina goza de especial predicamento en Alemania y en Italia. En el primer país, tanto el Tribunal Supremo Federal como el Tribunal Constitucional reconocen - de acuerdo con la Anscheinsbeweis - la necesidad de implementar el principio de igualdad de armas en el desarrollo del proceso de responsabilidad patrimonial, dicho de otra manera, el principio de igualdad material de las partes sobre la igualdad formal. En este sentido, se exige un plus de aportación probatoria a aquella parte, aunque sea demandada, que se encuentre favorecida por sus conocimientos técnicos, científicos o profesionales, obligándole a suministrar toda la información demostrativa de su actuar diligente.

En Alemania la doctrina del Anscheinsbeweis se remonta a principios del siglo xx. Así, el Tribunal Supremo del Reich (Reichsgericht) aplicó por vez primera esta teoría como una regla sobre la carga de la prueba en $1900^{44}$, aunque a partir de la Sentencia de 23 de noviembre de 1930 la consideró una regla sobre la valoración de la prueba ${ }^{45}$, que es como la aplica a día de hoy el Tribunal Supremo Federal (Bundesgerichtshof). En este sentido no puede dejar de mencionarse la Sentencia de este órgano jurisdiccional de 10 de julio de 1956, que dedujo la negligencia porque a

43 D. Hainmüller (1966), Der Anscheinsbeweis und die Fahrlässigkeitstat im heutigen deutschen Schadensersatzprozes, Tübingen: J. C. B. Mohr. Asimismo defienden el origen inglés de esta regla A. Laufs y W. Uhlenbruck (1999), Handbuch des Arztrechts, München: C. H. Beck'sche Verlagsbuchhandlung.

44 RG JW 1900, págs. 665-666.

45 RGZ 134, 237 [243]. 
una paciente de diecisiete años se le hubo de practicar una mastectomía porque dos años antes, al extirpársele un tumor, le habían quedado restos de apósitos que habían impedido su curación ${ }^{46}$.

Por su parte, en Italia tradicionalmente se ha calificado como injusto aquel daño que afecta a vida e integridad de las personas ${ }^{47}$. Así, la prima facie aparece por vez primera en la Sentencia 6141 de la Corte di Cassazione Civile de 21 de diciembre de 1978, reiterada en Sentencia de 16 de noviembre de 1988. Esta interpretación jurisprudencial apunta a que, en el ámbito sanitario cuando se trate de intervenciones normales que no exijan la solución de problemas técnicos complejos, o de terapia suficientemente experimentadas donde el logro del resultado es la regla general, el juez puede estimar mediante una presunción simple que el error que ha provocado el suceso sea per se suficiente para establecer la culpa del profesional.

\section{Daño desproporcionado}

Sin perjuicio de un análisis más exhaustivo en el epígrafe correspondiente a la responsabilidad médica, debe advertirse en este punto que el daño desproporcionado se define como una presunción de culpa cualificada que genera un mal resultado, cuando este, por su anormalidad y desproporción con lo que es usual, comparativamente, según las máximas de experiencia y el sentido común, revele inductivamente la penuria negligente de los medios empleados, conforme al estado de la ciencia y las circunstancias de tiempo y lugar, o el descuido en su conveniente y temporánea utilización ${ }^{48}$. En definitiva, la jurisprudencia en nuestro país ha desarrollado la teoría del daño desproporcionado como un mecanismo de presunción desfavorable para el demandado en el enjuiciamiento de la responsabilidad civil médica ${ }^{49}$.

\footnotetext{
46 No siempre esta teoría de la Anscheinsbeweis da lugar en todo caso a derecho a indemnizar. En una Sentencia anterior, de fecha 13 de diciembre de 1951, el Bundesgerichtshof había manifestado que la aparición de cuerpos extraños en el interior de un paciente que había sido intervenido quirúrgicamente no tiene por qué necesariamente implicar un error de tratamiento en que intervenga la culpa del médico, debiendo estar a las circunstancias del caso concreto, como el tamaño del cuerpo extraño olvidado y las circunstancias en que transcurrió la intervención (casos en los que una fuerte hemorragia dificulta la visualización de los cuerpos, o el caso de producirse una parada cardíaca y obligar al médico a prestar atención a la reanimación...).

47 P. Rescigno (2000), Manuale del diritto privato italiano, Roma: Jovene, págs. 687 y 688.

48 J. C. Galán CoRTés (2005), "Sentencia de 7 de octubre de 2001 (RJ 2004, 6229)», en Cuadernos Civitas de Jurisprudencia Civil, 68, págs. 831-846.

49 C. Villanueva Lupión «El alivio...», op. cit. Vid. también L. Sarrato Martínez (2008), «La doctrina del daño desproporcionado y su aplicación en el ámbito de la responsabilidad médico-sanitaria», Diario La Ley, 6968, 16 de junio.
} 
La doctrina del daño desproporcionado, también conocido como «resultado clamoroso», llegó a la jurisdicción contencioso-administrativa a partir de su asunción por la Sala Civil del Tribunal Supremo, quien a partir de sentencias del año 1996, la utilizó como criterio de valoración e imputación de la responsabilidad extracontractual en el ámbito sanitario.

En este sentido resulta obligado citar la Sentencia del Tribunal Supremo, Sala Primera, de lo Civil, de 26 de junio de 2006 (rec. 4072/1999), no solo porque recoge los orígenes de esta teoría en la jurisdicción civil, sino porque se refiere expresamente a la presunción de culpa: «La doctrina que funda la responsabilidad médica en la producción de un resultado desproporcionada, es reiterada en la jurisprudencia; así, entre otras, declara la Sentencia de 31 de enero de 2003: "La responsabilidad del médico demandado deriva esencialmente de la doctrina del resultado desproporcionado, del que se desprende la culpabilidad del autor, que ha sido consagrada por la jurisprudencia de esta Sala en numerosas sentencias: 13 de diciembre de 1997, 9 de diciembre de 1998, 29 de junio de 1999, 9 de diciembre de 1999 y 30 de enero de 2003, que dice esta última que el profesional médico debe responder de un resultado desproporcionado, del que se desprende la culpabilidad del mismo"».

Por su parte, en la jurisdicción contenciosa, la Sentencia del Tribunal Supremo, Sala Tercera, Sección 4ª de 2 de noviembre de 2012 (rec. 772/2012), entiende que:

[...] existente un resultado desproporcionado, totalmente inesperado y no contradicho o explicado coherentemente por el demandado, siendo que concurra además relación causal y que entre dentro de la esfera de actuación de este, cabía deducir sin duda alguna que existía conducta negligente, y, por tanto, una apariencia relevante de prueba de esta. Con posterioridad se fue afianzando —STS Sala Primera Civil de 8 de mayo de 2003-, sin perjuicio de momentos oscilantes y modulaciones. $\mathrm{Y}$ es que no cabía exclusivamente citar tal doctrina por el recurrente para deducir ya de por sí su aplicación por inversión de la carga de la prueba. Era necesario que por parte del demandado no se ofreciera y probara mediante prueba pericial de forma suficiente y fehaciente que el facultativo había tenido y seguido una actuación profesional acomodada a la lex artis ad hoc. En el caso de daño desproporcionado o resultado clamoroso el profesional médico está obligado a acreditar las circunstancias en que se produjo el daño por el principio de facilidad y proximidad probatoria (STS Sala Primera Civil de 10 de junio de 2008).

Respecto a la necesaria entidad del daño, es un criterio pacífico que el daño desproporcionado no consiste en la concurrencia de un daño 
muy grave, significativo o catastrófico, sino que requiere que se produzca un resultado anormal conforme a lo que es casual ${ }^{50}$, o un daño que presenta una anómala relación con el comportamiento ${ }^{51}$. Ciertamente en esta teoría la lesión no se mide por su intensidad, sino por la proporción con lo que debiera ser un daño en ese caso concreto. De hecho el Tribunal Supremo ha señalado que la teoría del daño desproporcionado se aplica a intervenciones de mínimo peligro ${ }^{52}$, y que el hecho de que se produzca un fallecimiento no convierte por sí solo al daño en desproporcionado ${ }^{53}$.

El daño desproporcionado, pese a ser una figura consolidada, no presenta una aplicación uniforme, toda vez que a menudo se confunde con el daño no deseado ${ }^{54}$.

\section{LA PRESUNCión DE CULPA EN EsPaña}

En nuestro país, tanto la jurisprudencia como la doctrina consultiva admiten la presunción de culpa, aunque en ocasiones no se refieran a ella expresamente. No obstante, también inadmiten la presunción de culpa en supuestos en los que no se cumplen los requisitos de la misma y se utiliza la expresión de res ipsa loquitur ${ }^{55}$ sin propiedad.

50 C. Díaz-Regañón García-Alcalá (2006), Responsabilidad objetiva y nexo causal en el ámbito sanitario, Granada: Comares, pág. 122.

51 L. Díez-Picazo y PONCE DE LeÓn, La culpa en la responsabilidad civil extracontractual. En R. De Ángel Yagüez y M. Yzouierdo Tolsada (2001), Estudios de responsabilidad civil en homenaje al Profesor Roberto López Cábana, Madrid: Dykinson, pág. 109.

52 Tal es el caso de la Sentencia del Tribunal Supremo, Sala Tercera, de lo ContenciosoAdministrativo, de 20 de junio de 2006 (rec. 167/2002), que reconoce el derecho a ser indemnizada a una madre por el fallecimiento de su hija, después de haberse sometido a intervención quirúrgica por cálculos en la vesícula.

53 La Sentencia del Tribunal Supremo, Sala Tercera, de lo Contencioso-Administrativo, de 4 de junio de 2013 (rec. 2187/2010) desestima una reclamación de responsabilidad de un paciente al que se le aplicó tratamiento de quimioterapia existiendo una infección en la herida quirúrgica, provocando la extensión y el agravamiento de la infección, que desencadenó el fallecimiento del paciente. En cambio, en su FD sexto esta Sentencia señala que «siendo en este caso indudable que el resultado causado fue letal o fatal y, por ende, gravísimo, no por ello puede calificarse sin más de "desproporcionado" a estos efectos, teniendo en cuenta que se trataba de una intervención quirúrgica a un paciente de 72 años con graves problemas coronarios que no pudio superar un derramamiento de bilis no detectado a pesar de haberse puesto todos los medios para ello y que acabó sufriendo varios infartos de miocardio».

54 A. ViCANDi MarTínez (2009), «El daño desproporcionado en la responsabilidad civil sanitaria. Un estudio jurisprudencial», en Nomos, 3, Universidad de Viña del Mar, Valparaíso (Chile), pág. 240.

55 Tal es el caso del Dictamen del Consejo de Estado 2188/2006, de 8 de noviembre de 2006, en el que un particular formula reclamación al Estado por funcionamiento anormal de la Administración de Justicia sobre la base de que el contenido y fallo de determinadas sentencias le resulta contradictorio, sin que pueda recurrir. El reclamante alega la elocuencia de los hechos a partir de la doctrina res ipsa loquitur, que el Consejo de Estado no entra a valorar, sino que 


\section{El deber jurídico de soportar un riesgo}

La responsabilidad patrimonial deriva de los daños causados con ocasión de la prestación de un servicio público. Con frecuencia el beneficio que el ciudadano recibe de la prestación del servicio público lleva aparejado un riesgo. Así, en el caso de una intervención quirúrgica el paciente se encuentra obligado a superar un período de convalecencia, pero en cambio no encuentra acomodo en ese deber una consecuencia desproporcionada, esto es, un resultado de fallecimiento ante una operación menor.

En consecuencia habrá que determinar los supuestos en que el daño sufrido por la víctima se encuentra o no en el deber jurídico de soportarlo, extremo que exige traer a colación de nuevo los principios informadores de la presunción de culpa: la proporcionalidad, la equidad y el cálculo probabilístico.

En este sentido es importante referirse al Dictamen del Consejo de Estado núm. 1743/1999, de 24 de junio de 1999, que resuelve un expediente de responsabilidad patrimonial por la actuación del Servicio de Cría Caballar y Remonta (Ministerio de Defensa). En particular el caso es el del fallecimiento de una yegua con ocasión de su inseminación artificial. Entiende el Consejo de Estado que el interesado «tenía el deber jurídico de soportar los riesgos normales derivados de la prestación de este servicio, siempre que el citado Servicio utilizara la diligencia y los medios exigidos por la lex artis».

En este supuesto el Alto Órgano consultivo no hace mención expresa a la presunción de culpa, si bien esta institución sí anida en su razonamiento cuando excluye cualquier otra causa del daño que no sea la negligencia del agente de la Administración: [...] no parece un riesgo propio de la intervención practicada (inseminación artificial) la peritonitis aguda directamente causada a la yegua por el paradista. Tampoco ha sido acreditado que esta se debiera a alguna circunstancia ajena a la esfera de control del paradista, ni que la conducta de la yegua o la de su propietario influyeran en modo alguno en la producción del daño. Resulta, en cambio, del expediente que el hecho lesivo fue causado por el brazo del paradista. Todo ello permite concluir que la peritonitis aguda se produjo a consecuencia de una violación de la lex artis.

desestima de plano porque «no puede basarse un funcionamiento anormal de la Administración de Justicia respecto a una resolución judicial con cuyo contenido no se está de acuerdo, en el hecho de la inexistencia de recursos frente a ella». 


\section{Caídas en la vía pública}

Porcentualmente un motivo nada desdeñable de reclamación de responsabilidad patrimonial consiste en las caídas en la vía pública, de manera que se reclama a la corporación municipal —en tanto que competente en materia de policía de obras, conservación de viales e infraestructura viaria (art. 25.2.d LBRL) - responsabilidad por el funcionamiento anormal (culpable) de ese servicio.

Como hemos adelantado, el criterio ha variado en los últimos años, pasando de una regla general indemnizatoria hasta la década de los noventa ${ }^{56}$ a un criterio restrictivo en el que se abandona el carácter objetivo para pasar a exigir culpa en el funcionamiento del servicio. En este sentido la Sentencia del Tribunal Supremo de 5 de junio de 1997, sin dejar de admitir el carácter objetivo de la responsabilidad, al mismo tiempo no exime que para que el daño concreto producido por el funcionamiento del servicio sea antijurídico sea preciso también que el riesgo inherente a su utilización haya rebasado los límites impuestos por los estándares de seguridad exigibles conforme a la conciencia social. Porque como ya es conocido, el Estado no puede convertirse en una aseguradora universal respecto a todos los eventos que en la vida ordinaria se produzcan.

En efecto, la jurisprudencia exige un deber de diligencia a la víctima del daño ${ }^{57}$ que es incompatible con la responsabilidad objetiva que

56 En la Sentencia de 4 de mayo de 1999 (ref. Arz. 4911), el Tribunal Supremo declaraba, como otras veces había hecho (vgr. Sentencias de 6 de octubre de 1998 —ref. Arz. 7813- y 13 de octubre de 1998 — ref. Arz. 7820-) que, aun cuando la jurisprudencia ha venido refiriéndose de modo general a un carácter directo, inmediato y exclusivo para particularizar el nexo causal entre la actividad administrativa y el daño o lesión que debe concurrir para que pueda apreciarse responsabilidad patrimonial de las administraciones públicas, no queda excluido que la expresada relación causal —especialmente en los supuestos de responsabilidad por funcionamiento anormal de los servicios públicos- pueda aparecer bajo formas mediatas, indirectas y concurrentes, circunstancia que puede dar lugar o no a una moderación de la responsabilidad (Sentencias de 8 de enero de 1967, 27 de mayo de 1984, 11 de abril de 1986, 22 de julio de 1988, 25 de enero de 1997 y 26 de abril de 1997, entre otras) y que entre las diversas concepciones con arreglo a las cuales la causalidad puede concebirse, se imponen, en materia de responsabilidad patrimonial de la Administración, aquellas que explican el daño por la concurrencia objetiva de factores cuya inexistencia, en hipótesis, hubiera evitado aquel (Sentencia de 25 de enero de 1997), por lo que no son admisibles, en consecuencia, concepciones restrictivas que irían en contra de las administraciones públicas (Sentencia de 5 de junio de 1997).

57 Según la Sentencia 551 de 23 de julio de 2009 del Tribunal Superior de Justicia de Illes Balears (rec. 96/2009), «el peatón también tiene un deber de diligencia, siendo ésta la que, en expresión del Código Civil, corresponde al buen padre de familia. Ese deber de diligencia, que se desprende de lo previsto en el artículo 1902 del Código Civil y que bien cabría especificar mediante ordenanza municipal, al fin, comporta que el peatón tiene que ser consciente de sus actos, esto es, que el peatón, desde luego, tiene que ser prudente y, por tanto, que el peatón tiene que mirar por dónde camina y qué es lo que pisa. 
pudiera nacer a partir del resultado lesivo. Puede citarse, por todas, la Sentencia del Tribunal Supremo de 2 de marzo de 2006 por ser ilustrativa de este giro en la consideración de la responsabilidad ${ }^{58}$.

Ahora bien, y en lo que a nosotros interesa, esta consideración culposa lleva consigo - si no la presunción de culpa tal cual- a lo sumo la exigencia de que la Administración pruebe su diligencia. Por ello es reveladora la Sentencia del Tribunal Superior de Justicia del País Vasco, Sala de lo Contencioso-Administrativo, Sección $3^{\mathrm{a}}$, de 18 de febrero de 2008 (rec. 1875/2001), que en su FJ cuarto señala que «la Administración demandada no ha probado las causas exoneradoras de su responsabilidad». Esta afirmación, lejos de ser inofensiva, encierra la regla de la facilidad y disponibilidad probatoria, que es el fundamento de la deducción de negligencia. Esta Sentencia no habla de la presunción de culpa ni de ninguna teoría de elocuencia de los hechos; sin embargo, la aplica claramente sin referirse a ella.

La doctrina consultiva no es ajena a esta consideración, debiéndose citar el Dictamen del Consejo Consultivo de Castilla-La Mancha 252/2012, de 24 de octubre, que hace suyos los criterios jurisprudenciales para advertir que si un administrado cae al suelo a causa de una irregularidad insignificante de la acera, debe soportar las consecuencias

\footnotetext{
«Por consiguiente, en todos los casos de accidentes por mal estado de la vía pública no basta con la constatación del desperfecto, sino que debe también ponderarse en qué medida ha cooperado en el daño - o ha sido decisiva - la actuación negligente de la víctima».

58 «Y aun en el caso de que se considerase la posible existencia de un defecto de señalización, las circunstancias concurrentes impiden la imputación objetiva a la empresa demandada del daño producido, pues como destaca la STS de 11 de noviembre de 2005, necesariamente el comportamiento humano, en la generalidad de los casos, según la regla id quod plerumque accidit [las cosas que ocurren con frecuencia] implica soportar los pequeños riesgos que una eventual falta de cuidado y atención comporta en la deambulación por lugares de paso, por lo que, cuando se aprecia dicha omisión, como ocurre en el caso examinado en función de las circunstancias que se acaban de destacar de visibilidad de los trabajadores y previo paso de la accidentada por la misma zona, cabe, bien la moderación de la responsabilidad del causante mediante la introducción del principio de concurrencia de culpas, bien la exoneración del causante por circunstancias que excluyen la imputación objetiva cuando el nacimiento del riesgo depende en medida preponderante de aquella falta de atención, como ocurre en el caso enjuiciado, en el que la obligación de una señalización adicional de la manguera de pequeño tamaño que se había tendido solo podría implicar, de existir — dadas las precauciones tomadas consistentes en destacar la visibilidad de los trabajadores que la manejaban-, una falta de diligencia de carácter irrelevante por ser muy inferior en su virtualidad determinante del accidente al riesgo asumido por la actora al circular con falta de atención a las circunstancias de la vía.

»En suma, no solo resulta discutible la existencia de culpabilidad por parte de los trabajadores de la empresa, sino que en el caso falta la causalidad en su secuencia jurídica o de posibilidad de atribución del daño, porque la caída sufrida no puede imputarse a la conducta de los trabajadores, sino que opera la regla excluyente —criterio de valoración de "imputación objetiva"- del "riesgo general de la vida" (tomado en cuenta también, además de en la sentencia citada, en las también recientes sentencias de 21 de octubre de 2005 y 5 de enero de 2006). Y si no hay causalidad, como declara esta última sentencia, no cabe hablar, no ya de responsabilidad subjetiva, sino tampoco de responsabilidad por riesgo u objetivada».
} 
de esa caída, en tanto que la lesión no será antijurídica; y que no puede pretenderse que la superficie de las aceras o sus bordillos se encuentre en un absoluto alineamiento, totalmente rasante y carente de la más mínima irregularidad ${ }^{59}$.

Es importante advertir que, si se exonera a la Administración de responder, es porque se presume la negligencia de la víctima. Por tanto, en estos casos sí podemos afirmar que existe presunción de culpa, si bien del perjudicado. A la víctima le resulta exigible un nivel de atención, "pues de otra forma se estaría haciendo un llamamiento a la falta de responsabilidad individual, pese a constituir esa responsabilidad uno de los fundamentos de la vida social» ${ }^{60}$.

\section{Lesiones sufridas en establecimientos públicos}

En la misma línea que en el caso anterior, las lesiones sufridas en establecimientos públicos también presentan el límite del deber de diligencia de la víctima, que le debe resultar exigible.

Al igual que en las caídas en la vía pública, no se puede presumir la culpa si no se acredita la relación de causalidad.

Un ejemplo típico de daños sufridos en el interior de establecimientos destinados a la prestación de servicios públicos es el causado con las puertas de ascensores, que comprenden desde traumatismos hasta amputaciones. Tanto la jurisprudencia como la doctrina consultiva coinciden en señalar que no es posible plantearse el elemento subjetivo de la responsabilidad si no existe relación de causalidad; y con frecuencia la imposibilidad de acreditar esta última se erige en el fundamento para desestimar la reclamación.

En el primer caso pueden citarse las Sentencias de la Audiencia Nacional de 6 de febrero de 2006 (rec. 668/2003) y de 14 de noviembre de 2007 (rec. 125/2006), que desestiman sendas reclamaciones por lesiones

59 Este Dictamen hace referencia a la Sentencia del Tribunal Superior de Justicia de Castilla y León, Sala de lo Contencioso-Administrativo, de 23 de diciembre de 2005 (rec. 303/2004), a cuyo tenor: «La posibilidad de caerse en una acera surge desde el mismo momento en que se transita por ella, sin que las consecuencias de esa caída puedan ser imputadas sin más a la administración responsable. Del mismo modo que existe la posibilidad de tropezar en el interior de una vivienda. Los tropiezos, sin mayores consideraciones, son consustanciales al deambular humano y la administración (o el particular si se tropieza en su vivienda o en su finca) no tiene el deber de indemnizar la totalidad de los tropiezos que se producen en las calles. Únicamente indemnizará aquellos tropiezos que generen lesiones antijurídicas; que el "tropezado", el ciudadano no tenga la obligación de soportar, y esto se determinará por medio de los criterios antedichos».

60 Sentencia del Tribunal Superior de Justicia de Cataluña, Sala de lo Contencioso-Administrativo, de 20 de noviembre de 2006 (rec. 2113/2001). 
causadas por el cierre de puerta de ascensor en las delegaciones de la Agencia Estatal de Administración Tributaria de León y Huelva, respectivamente. Este es el criterio que adopta la Sentencia del Juzgado de lo Contencioso-Administrativo núm. 5 de Asturias de 30 de mayo de 2007 (rec. 448/2006), que desestima la reclamación por accidente sufrido al cerrarse las puertas del ascensor del Centro de Salud de La Felguera ${ }^{61}$, o la Sentencia del Tribunal Superior de Justicia de Andalucía, Granada, de 3 de enero de 2011 (rec. 2972/2003), por daños causados en una muñeca al cerrarse las puertas del ascensor del edifico de los Juzgados de lo Contencioso-Administrativo, por no haberse acreditado cuál hubiera podido ser el anormal funcionamiento del servicio público ${ }^{62}$.

\section{Suicidio en establecimientos públicos}

La autolesión y el suicidio en establecimientos públicos —comisarías, centros penitenciarios y hospitales - no constituyen una novedad en materia de reclamación de responsabilidad. En sede doctrinal algunos autores se han referido al caso de los novios de Granada, que fallecieron porque un enfermo mental se arrojó desde una ventana del Hospital San Juan de Dios, de la Diputación Provincial, cayendo encima de una pareja de novios, causándole la muerte a él y lesiones graves a ella ${ }^{63}$.

Con carácter general nuestra jurisprudencia estima las reclamaciones por suicidios en establecimientos públicos, pero no siempre con fundamento en la presunción de culpa.

61 «Cuando se utiliza un ascensor (al igual que una escalera o se deambula por la vía pública) ha de tenerse la diligencia y cuidado exigible a todo usuario, sin que en este caso se haya probado la imposibilidad del usuario para percatarse, según la naturaleza del ascensor, de algo tan lógico y habitual como que las puertas del ascensor del Centro de La Felguera se cierran automáticamente. En suma, que en la mejor de las hipótesis verosímiles más bien estamos ante un supuesto de descuido o falta de reacción de la reclamante, por lo que nada puede reprocharse a la Administración».

62 «En modo alguno puede representarse la Sala — con los elementos de que se disponencuál hubiera podido ser el anormal funcionamiento del ascensor que la interesada menciona como origen o causa del daño, cuando en estos tiempos es ya de conocimiento y alcance del común de las personas, la presencia en los ascensores del mecanismo de cierre automático de puertas comandado por células fotoeléctricas; y sin que tan siquiera se haya llegado a evidenciar a través de la prueba testifical practicada en los autos, en qué pudo consistir el defecto de funcionamiento producido - introduce proverbial incertidumbre el hecho denunciado de que el ascensor golpeara varias veces la muñeca lesionada-, limitándose a afirmar en la misma que «[...] cuando iban a entrar en el ascensor la puerta se cerró atrapando el brazo izquierdo de la Sra. Aida».

63 A. Jiménez-Blanco Carrillo de Albornoz (1986), "Responsabilidad administrativa por culpa in vigilando o in ommittendo», en Revista del Poder Judicial, 2, pág. 120. F. GARrido FaLla (1989), "La constitucionalización de la responsabilidad patrimonial del Estado», Revista de Administración Pública, 119, págs. 7 y ss. 
En efecto, el ciudadano que se quita la vida o se autolesiona en un centro oficial es víctima del funcionamiento anormal del servicio público, si bien no por deducción de negligencia, sino por culpa in vigilando. El agente policial que tenía que custodiar al interno, no lo ha hecho o no lo ha hecho correctamente.

Así, la Sentencia del Tribunal Supremo de 12 de marzo de 1975, de los novios de Granada, declara que «el daño resulta patrimonial, atribuible a la Corporación, que no puede exonerarse del mismo invocando, como ha hecho, su imputación a la acción de tercero, puesto que el perturbado, al hallarse internado en el hospital (aunque no fuese en calidad de enfermo mental, sino para tratamiento médico), no constituía un agente extraño al funcionamiento del centro, sino un usuario interno que como tal se integraba en su organización y disciplina».

Distinto es el supuesto del paciente que ingresa en un centro hospitalario con un parte médico en el que se le diagnostican ideas de suicidio. $\mathrm{Al}$ paciente se le practica el ingreso, para lo cual se examina el parte que llevaba, y una vez se le conduce a un departamento de reconocimiento de urgencias, mientras su hermano acompañante va a estacionar el vehículo, el paciente desaparece durante cinco horas, para encontrarlo ahorcado en otra dependencia del hospital. Este es el caso que enjuicia la Sentencia del Tribunal Supremo, Sala Tercera, de lo Contencioso-Administrativo, de 4 de octubre de 1999 (rec. 5257/1995), que hace hincapié en que el hospital ha comprobado un parte médico en el que precisamente se indica una tendencia suicida, motivo por el cual la responsabilidad patrimonial va más allá de una culpa in vigilando.

En este punto el Tribunal Supremo deduce la negligencia del personal sanitario que verificó el volante y no tomó en serio su contenido: «la integración del paciente en el ámbito organizativo del hospital, para lo que resulta suficiente la recepción en el servicio de guardia con examen del parte acompañado expresivo de su situación médica, lleva a considerar que los acontecimientos posteriores se producen en el seno de la organización del mismo y, por consiguiente, y prescindiendo de nuevo de su carácter evitable, en ningún caso pueden ser imputados a una fuerza mayor ajena a dicho ámbito de organización».

\section{La responsabilidad en la edificación}

Aunque sea más propia de la responsabilidad civil que de la patrimonial, dada su naturaleza predominantemente contractual, analizamos en este punto si la responsabilidad de los agentes de la edificación guar- 
da relación con la presunción de culpa, dado que la misma se regula en una norma administrativa especial, cual es la Ley 38/1999, de 5 de noviembre, de Ordenación de la edificación.

En efecto, el art. 17 LOE obliga a las personas físicas o jurídicas que intervienen en el proceso de la edificación a responder de los daños materiales ocasionados en el edificio en diferentes plazos en función del tipo de daño ${ }^{64}$, independientemente de las responsabilidades contractuales que hubieran asumido.

Un sector doctrinal califica como de presunción de culpa los daños que pudieran aparecer durante los plazos consignados. Así, sobre la base de la reforma del Código Civil francés operada por el 4 de enero de 1978 a partir del Informe Spinetta ${ }^{65}$, Vigo Morancho entiende que «para poder ser ejercitada con posibilidad de viabilidad la acción de responsabilidad es requisito imprescindible que los vicios o defectos que se manifiesten durante la vigencia del plazo decenal, que, en definitiva, es revelador de una presunción de culpa del contratista o arquitecto director, según las causas, de naturaleza iuris tantum» ${ }^{66}$. Para este autor la presunción de culpa en esta responsabilidad se fundamenta en que el agente de la edificación solo puede exonerarse probando que el daño proviene de una causa ajena, ya sea en el hecho de un tercero, en el caso fortuito o en la fuerza mayor ${ }^{67}$.

\section{La responsabilidad en el deporte}

La responsabilidad en el deporte comprende desde la víctima que participa en una competición, es decir, la práctica en sí, hasta la organización del evento deportivo, pasando por los espectadores.

${ }^{64}$ La responsabilidad es decenal, trienal y anual. Así, durante diez años, los agentes de la edificación responden de los daños materiales causados en el edificio por vicios o defectos que afecten a la cimentación, los soportes, las vigas, los forjados, los muros de carga u otros elementos estructurales, y que comprometan directamente la resistencia mecánica y la estabilidad del edificio. En cambio, lo hacen durante tres años por los daños materiales causados en el edificio por vicios o defectos de los elementos constructivos o de las instalaciones que ocasionen el incumplimiento de los requisitos de habitabilidad del apartado 1, letra c), del artículo 3. Por último, el constructor también responderá de los daños materiales por vicios o defectos de ejecución que afecten a elementos de terminación o acabado de las obras dentro del plazo de un año.

65 C. Gómez de la Escalera (1994), La responsabilidad civil de los promotores, constructores y técnicos por los defectos de construcción, Barcelona: J. M. Bosch, pág. 44.

66 A. Vigo Morancho (2001), "Las responsabilidades decenal, trienal y anual en la Ley de Ordenación de la Edificación», en Diario La Ley, Sección Doctrina, ref. D-254, t. 7, Editorial La Ley, La Ley 1419/2002.

67 Sobre la fuerza mayor en la responsabilidad patrimonial, vid. C. BARRERo Rodríguez (2009), Fuerza mayor y responsabilidad administrativa extracontractual, prólogo de Pedro Escribano Collado, Cizur Menor: Thomson Reuters-Aranzadi. 
En el primer supuesto y al hilo de lo que hemos dejado apuntado en el capítulo introductorio, la práctica del deporte supone la asunción de un riesgo, extremo que no se da en el espectador que observa pasivamente ni en la víctima de un daño que ocasione la organización del evento.

El ejercicio del deporte constituye una actividad de riesgo per se, que compromete un bien jurídico de rango constitucional como es la integridad física ${ }^{68}$. Ahora bien, y como se encarga de señalar la Sala Primera del Tribunal Supremo, «el riesgo, por sí solo, no puede constituirse en fuente única de responsabilidad» (Sentencia 612/2007, de 6 de junio). De ahí que en consecuencia haya como mínimo que traer a colación el análisis del elemento subjetivo en la responsabilidad en el deporte.

Con base en la teoría de la asunción de riesgos ${ }^{69}$, al deportista se le considera investido de un nivel de conocimiento que le permite observar unas reglas de cuidado y una disciplina deportiva, de manera que asume con total libertad un riesgo conocido de antemano. Por ello toda lesión que encaje dentro del riesgo típico difícilmente será indemnizable, mientras que, por el contrario - con base en la teoría del daño desproporcionado-, aquella lesión que se exceda de la normalidad será calificada como antijurídica y la víctima no tendrá el deber legal de soportar.

\section{Lesiones causadas por las fuerzas y cuerpos de seguridad}

El artículo 5.2.c de la Ley Orgánica 2/1986, de 13 de marzo, de Fuerzas y Cuerpos de Seguridad, contempla entre los principios básicos de actuación de los miembros de las fuerzas y cuerpos de seguridad en sus relaciones con la comunidad el deber de actuar en el ejercicio de sus funciones con la decisión necesaria, y sin demora cuando de ello dependa evitar un daño grave, inmediato e irreparable, rigiéndose al hacerlo por los principios de congruencia, oportunidad y proporcionalidad en la utilización de los medios a su alcance.

68 F. DE LA TORRe Olid (2008), «Derecho y deporte. Particular referencia a los accidentes deportivos. Responsabilidad civil y riesgos en el deporte», Diario La Ley, 7081, sección Doctrina, 22 de diciembre, año XXIX, ref. D-375, Editorial La Ley.

69 Aplicada al deporte, esta teoría se acuña en la Sentencia del Tribunal Supremo, Sala Primera, de lo Civil, de 22 de octubre de 1992 (rec. 1561/1990), que desestimó una reclamación de responsabilidad de un jugador de pala frente a su contrincante, por propinarle un golpe que desencadenó la pérdida del ojo. Esta misma teoría se aplicó en la Sentencia de la misma sala y Tribunal de fecha 9 de marzo de 2006, para desestimar la reclamación por la muerte de un jugador de golf como consecuencia del impacto de una pelota lanzada desde otra calle, separada por una arboleda, sin apreciar negligencia en el lanzador demandado. 
En este sentido la jurisprudencia del Tribunal Supremo ha verificado que las lesiones corporales provocadas en un caso de detención o de disolución de una manifestación presumen la culpa de la Administración, a la que corresponde la prueba de su actuar diligente.

Así, debe citarse la Sentencia del Tribunal Supremo, Sala Tercera, de lo Contencioso-Administrativo, de 20 de enero de 1998 (rec. 5284/1993), que desestima el recurso de casación interpuesto por el abogado del Estado contra la Sentencia de la Audiencia Nacional de 20 de marzo de 1993, que reconoció una indemnización por importe de siete millones de pesetas en favor de un ciudadano que recibió el impacto de una pelota de goma de una carga policial en el transcurso de una manifestación que habían sido previamente autorizada. Como consecuencia de esta lesión perdió la visión del ojo ${ }^{70}$.

\section{Daños causados por la ejecución de obras públicas}

Con carácter general la jurisprudencia y la doctrina consultiva vienen desestimando que las molestias que supone la realización de obras públicas constituyan un daño antijurídico. Por todas, puede citarse la Sentencia del Tribunal Supremo, Sala Tercera, de lo Contencioso-Administrativo, Sección 6 ${ }^{\mathrm{a}}$, de 23 de marzo de 2009 (rec. 10236/2004), en el conocido caso Hotel Miguel Ángel de Madrid, de obligada referencia por cuanto recoge de manera completa la fundamentación jurídica de esta clase de daños, tanto la regla general como las excepciones, que pasan por la singularidad del daño o la superación del plazo de ejecución previsto por causas imputables a la Administración. En efecto, esta Sentencia hace acopio nuevamente de los estándares de negligencia, concebidos como la frontera entre la indemnidad y la responsabilidad.

70 La Sentencia no ofrece lugar a dudas en la apreciación de la deducción de negligencia en este caso: «la jurisprudencia de esta sala tiene declarado con reiteración que la participación en una manifestación solo comporta la obligación de arrostrar el perjuicio originado por los actos de las fuerzas de seguridad encaminadas a garantizar el cumplimiento de la ley en aquellos casos en que el recurrente voluntariamente se coloca en una situación de riesgo por tomar parte en una manifestación ilegal o por participar o exponerse imprudentemente a actos violentos durante una manifestación autorizada o no (S 2 Mar. 1996, entre otras), si bien estas circunstancias corresponde acreditarlas a la Administración a quien se imputa la responsabilidad, por constituir hechos obstativos a la pretensión de responsabilidad patrimonial, la cual está en este caso en íntima relación con el libre ejercicio del derecho fundamental de reunión y manifestación que el poder público debe proteger y que podría resultar coartado si, para reclamar por los daños padecidos, se impusiese a quienes lo ejercen la prueba negativa de no haber participado o incurrido en actos violentos durante el desarrollo de una manifestación no ilegal». 
Estos estándares de negligencia, indicativos de la presunción de culpa, pueden verificarse con mayor intensidad si la obra pública trae causa de una infracción administrativa. Tal es el caso del Dictamen 95/2015, de 22 de julio de 2015, del Consejo Consultivo de las Illes Balears, que estima la reclamación de responsabilidad patrimonial de varios establecimientos comerciales como consecuencia de la demolición del puente de Es Riuet de Porto Cristo (Manacor).

En efecto, la Sentencia del Tribunal Superior de Justicia de Illes Balears 81/2007, de 6 de febrero de 2007 (rec. 663/2003), anula sendos Decretos de Alcaldía en virtud de los cuales se aprobaba el proyecto técnico y se adjudicaban las obras para la construcción de un puente sobre Es Riuet del núcleo costero de Porto Cristo. Por ello es que las obras de demolición se realizan en ejecución de Sentencia, que anula por no ser conforme a derecho la construcción del puente.

En consecuencia, el Consejo Consultivo aprecia que en este caso de demolición de unas obras ilegales, los comerciantes que se ven afectados por ruidos, polvo y escombros no tienen el deber jurídico de soportar estas molestias, que van más allá del estándar de diligencia, porque traen causa de una obra declarada ilegal.

\section{LA PRESUNCIÓN DE CULPA EN LA RESPONSABILIDAD MÉDICA}

Dada su especial particularidad, en la medicina el error forma parte de la estadística. Ahora bien, no cualquier error es sinónimo de negligencia, de manera que habrá que analizar en cada caso cuándo el error médico es causante de un daño antijurídico que haya que indemnizar ${ }^{71}$.

1. Responsabilidad por culpa y lex artis como estándar objetivo de diligencia

A) Daño desproporcionado y lex artis ad hoc

Un parámetro que permite objetivar la actuación de la Administración Pública en la prestación sanitaria consiste en la lex artis ad hoc.

71 Sobre la inevitabilidad del error médico y su intrínseca asociación a la condición humana, vid. L. T. Khon, J. M. Corrigan y M. S. Donaldson (1999), To Err is Human, Washington D.C.: National Academy Press. 
Como ciencia que es, la medicina se halla sujeta a las reglas propias de su oficio, de manera que su transgresión implica responsabilidad. La lex artis se convierte así en el criterio de normalidad, que ha de infringirse en la realización del servicio sanitario para que haya lugar a la obligación de indemnizar, que, a su vez, permite valorar la corrección de los actos médicos ${ }^{72}$.

El Tribunal Supremo atribuye a la lex artis la cualidad de criterio valorativo de la corrección del concreto acto médico ejecutado por el profesional de la medicina, ciencia o arte médica, que tiene en cuenta las especiales características de su autor, de la profesión, de la complejidad y trascendencia vital del paciente y, en su caso, de la influencia en otros factores endógenos (estado o intervención del enfermo o de la misma organización sanitaria) para calificar dicho acto de conforme o no con la técnica normal requerida ${ }^{73}$.

Estos protocolos de actuación de la lex artis se convierten así en un estándar objetivo que permite medir el grado de diligencia del facultativo: cualquier actuación que se aparte de la lex artis es en consecuencia reveladora de culpa y por ello genera el deber de indemnizar.

No obstante lo anterior, no puede pasar desapercibido que el daño desproporcionado y la lex artis son incompatibles a la hora de determinar responsabilidad.

En efecto, el daño desproporcionado aflora cuando, habiendo respetado escrupulosamente la lex artis, sin embargo se produce un efecto lesivo. En ese caso es cuando resulta aplicable la doctrina del daño clamoroso o anormal ${ }^{74}$.

72 A. I. Berrocal Lanzarot (2011), «A propósito de la responsabilidad civil médica. La teoría de la pérdida de oportunidad y del resultado o daño desproporcionado», en Revista de la Escuela de Medicina Legal, febrero, pág. 33.

73 Sentencia de la Sala Primera, de lo Civil, de 11 de marzo de 1991 (autos 741/1986).

74 En este sentido, el Consejo de Estado tiene declarado en su Dictamen de 3 de junio de 1999 que «este carácter objetivo, tal y como en reiteradas ocasiones ha puesto de manifiesto la jurisprudencia del Tribunal Supremo y la doctrina del Consejo de Estado, no implica que todos los daños producidos en los servicios públicos sanitarios sean indemnizables, pues ello llevaría a configurar la responsabilidad administrativa en estos casos, de forma tan amplia y contraria a los principios que la sustentan, que supondría una desnaturalización de la institución. Así pues, de acuerdo con dicha doctrina, para apreciar la existencia de responsabilidad patrimonial es preciso acudir a parámetros como la lex artis, de modo que tan solo en el caso de una infracción de esta ley cabrá imputar a la Administración de la cual dependen los servicios sanitarios la responsabilidad por los perjuicios causados. En el caso de que no se infrinja la lex artis, ha de concluirse que tales perjuicios no son imputables a la Administración y han de ser soportados por el particular, sin que generen, en modo alguno, el derecho a percibir una indemnización».

La distinción entre daño desproporcionado y lex artis la aborda la Comisión Jurídica Asesora de Cataluña en su Dictamen 201/2011 cuando señala que «no es suficiente con expresar que no hubo mala praxis, porque, en el caso de que se hubiera producido, habría constituido, en sí misma, el título de imputación necesario, sino que hace falta que se explique por qué, a 


\section{B) Daño desproporcionado y presunción de culpa}

En materia de prueba en la práctica asistencial resulta predicable en toda su extensión la asimetría de la información entre el paciente y el facultativo, la posición privilegiada de este último para acceder a los hechos, que se corresponde con la dificultad intrínseca del primero, abocado en términos generales a una probatio diabolica. De ahí que las reglas de la disponibilidad y facilidad probatorias se conviertan en un requisito de justicia material, porque —al decir de ATAz LóPEZ — «es necesaria cierta flexibilidad en cuanto a la exigencia de la prueba, ya que la certeza es difícil de obtener; y así, confiar en el buen sentido del juzgador, que, con los datos de los que disponga, los probados por el enfermo y los probados por el médico, pueda llegar a presumirse la causalidad en determinados casos, siempre que se proporcione en la prueba un indicio de ella, suficiente para establecer la presunción en base a la común experiencia».

En el daño desproporcionado confluyen todos los requisitos para la presunción de culpa. En primer lugar, la responsabilidad no es objetiva, sino subjetiva en función del cumplimiento o incumplimiento de la lex artis. El único dato cierto consiste en la lesión que ha sufrido la víctima, si bien se desconoce la causa, que por otra parte entra dentro del ámbito de influencia del eventual causante de la misma.

A partir de aquí, si se verifica el daño desproporcionado, la jurisprudencia deduce la negligencia en la prestación del servicio por la simple razón de que no podría haberse dado un resultado tan desproporcionado de no haber mediado culpa o negligencia ${ }^{75}$.

pesar de la buena praxis, ha tenido lugar el daño inusual y desproporcionado denunciado con la patología de origen: [...] El Tribunal Supremo, concretamente, las salas Primera y Tercera, ha reflexionado sobre esta cuestión y ha establecido estas reglas: la admisibilidad del daño desproporcionado exige la ausencia de una explicación coherente por parte de la Administración (Sentencias del Tribunal Supremo, Sala Primera, de 9 de diciembre de 1999 y de 16 de abril y 5 de diciembre de 2007), y no se aprecia aquel daño cuando exista tal explicación (Sentencia de 30 de junio de 2009), mientras que en la Sentencia de 10 de julio de 2007, de la Sala Tercera, se rehusó el daño mencionado teniendo en cuenta las patologías previas y concurrentes del paciente».

75 Este es el caso de la Sentencia del Tribunal Supremo, Sala Tercera, de lo ContenciosoAdministrativo, de 10 de abril de 2014 (rec. 2029/2012), que analiza el nacimiento de un niño con secuelas pese a no haberse infringido la lex artis. El Tribunal Supremo confirma la Sentencia de la Audiencia Nacional de 14 de marzo de 2012 y hace suyo en su FJ Segundo el razonamiento de este último órgano jurisdiccional: «el criterio del daño desproporcionado, recogido por la jurisprudencia contencioso-administrativa (entre otras, Sentencias de 20 de junio de 2006 o de 10 de julio de 2007), implica, esencialmente, que, ante ciertos datos empíricos y en ausencia de una prueba directa, puede deducirse la infracción de la lex artis cuando las circunstancias y el sentido común indican que el resultado lesivo "es inusual” en relación con intervenciones y actuaciones similares, suponiendo, por tanto, un juicio probabilístico basado en las máximas de experiencia». 


\section{Alcance y límites de la presunción de culpa en el daño} desproporcionado

Precisamente por tener como efecto la alteración de las reglas de la carga de la prueba, el daño desproporcionado tiene que ser objeto de interpretación restrictiva, sin que pueda aplicarse al margen de una fundamentación jurídica ${ }^{76}$.

Por este motivo vamos a analizar a continuación los supuestos en los que puede darse esta doctrina del daño desproporcionado, si bien teniendo en cuenta su alcance y sus limitaciones.

\section{A) Infecciones nosocomiales}

Las infecciones intrahospitalarias, también denominadas nosocomiales (del latín, nosocomium, hospital de enfermos), son aquellas contraídas en un centro de salud (no solo hospitales) por un paciente internado por una dolencia distinta a esa infección. Comprenden tanto las causadas por factores exógenos al paciente (microorganismos presentes en un quirófano) o endógenos del mismo, es decir, presentes en su cuerpo, si bien manifestados y desarrollados a raíz del ingreso. Cronológicamente resulta indiferente que la infección se manifieste durante la estancia hospitalaria o con posterioridad, siempre que la misma no se hubiere manifestado antes del ingreso ni el paciente se encontrara en período de incubación. También se incluyen en las infecciones nosocomiales las contraídas por el personal facultativo y por los visitantes al centro de salud.

Tanto la jurisprudencia de la Sala Primera del Tribunal Supremo como la doctrina consultiva resultan explícitas en atribuir la deducción de negligencia a las infecciones intrahospitalarias, tal como resulta de la Sentencia del Tribunal Superior de Justicia del Principado de Asturias,

76 Al decir de la Comisión Jurídica Asesora de Cataluña en su Dictamen 244/2007, «la doctrina jurisprudencial ha reservado el concepto del daño desproporcionado para aquellos casos en que el resultado no tiene ninguna justificación explicable, vista la patología del paciente. Se trataría de actuaciones médicas que no comportan ningún riesgo y, no obstante, los resultados no solo no son esperados, sino que son totalmente injustificables y normalmente desvinculados con la patología relacionada con la intervención, por lo cual comportan una cierta presunción de culpa. Como se dijo en el Dictamen 108/06 y se reiteró en el Dictamen 209/09, los ejemplos de la persona que muere como consecuencia de una inyección intramuscular mal inyectada (Sentencia del Tribunal Supremo, Sala Tercera, de 11 de mayo de 1999), o el supuesto del joven jugador de fútbol que, como consecuencia de una fractura simple del peroné y de la intervención quirúrgica subsiguiente, se le gangrena la pierna y se la tienen que amputar son supuestos emblemáticos». 
Sala de lo Contencioso-Administrativo, Sección 1 ${ }^{\mathrm{a}}$, de 8 de junio de 2011 (rec. 979/2008) ${ }^{77}$.

En estos casos la presunción de culpa se fundamenta en la interpretación de que se ha roto la cadena de asepsia, razonando que -pese a que las medidas generales propuestas por el centro de salud sean correctas- si se hubieran llevado a cabo de forma estricta no se habría producido la infección, por lo que la infección hospitalaria era previsible y evitable si no se hubiera roto aquella cadena de asepsia y se extremasen las medidas de asepsia y todos los controles de prevención de infecciones.

\section{B) Transfusiones}

Directamente relacionado con las infecciones intrahospitalarias, aunque guardando su especialidad, resulta obligado plantear el supuesto de transmisión de enfermedades con ocasión de transfusiones sanguíneas.

Una vez más la prueba ante una infección contraída con ocasión de una transfusión sanguínea se presenta muy difícil. En estas situaciones la jurisprudencia hace acopio de la presunción de culpa, no sin antes valorar que en el tiempo que media entre la transfusión y la manifestación de la infección no se haya producido otro factor de riesgo de contagio.

La jurisprudencia y la doctrina consultiva no son ajenas al conocimiento científico, de manera que no son infrecuentes los supuestos en que se amparan en el art. 141.1 LRJ-PAC para apreciar la ruptura del nexo causal. Tal es el caso del Dictamen del Consejo de Estado 2508/2004, de 18 de noviembre de 2004, que considera que procede desestimar la reclamación de responsabilidad patrimonial porque «el staphilococus aureus no es una bacteria que tenga necesariamente su origen en el propio material quirúrgico o en el recinto hospitalario, [sino

77 «En orden a las enfermedades nosocomiales, resulta aplicable el principio de presunción o probabilidad de culpa, apreciable en supuestos de infecciones contraídas o reactivadas en el propio medio hospitalario, como en tal sentido lo declaran las Sentencias de la Sala Primera del Tribunal Supremo de 21 de julio de 1997, 9 de diciembre de 1998 y 5 de febrero de 2001, en distintos supuestos en los que se plasma el principio de la responsabilidad objetiva de la Administración. Igualmente, la Sentencia del Tribunal Supremo de 22 de abril de 2003, declaró la responsabilidad patrimonial de la Administración, derivada de acto sanitario por contagio hospitalario, al mantener que aunque los datos acreditados no prueban de una manera absolutamente indubitada el nexo causal, lo cierto es que las distintas circunstancias concurrentes cabe llegar razonadamente a la conclusión de que la causa eficiente de la producción del daño era el contagio intrahospitalario, al no mediar otros riesgos concurrentes para adquirir la infección». 
que] por el contrario se encuentra normalmente en la piel o en la cavidad nasal de los pacientes».

Otra cosa es que, a partir del momento en que tales pruebas científicas sí se hacen en los hospitales (el test del sida a partir de 1985 y el de hepatitis C a partir de 1990), la responsabilidad deviene culpable y en consecuencia un contagio es indicativo de presunción de culpa ${ }^{78}$.

C) Retrasos y errores de diagnóstico. La pérdida de oportunidad terapéutica

La jurisprudencia y la doctrina consultiva han hecho acopio de un abundante corpus sobre los retrasos y errores en el diagnóstico, que hacen que la patología del paciente alcance un estadio o bien difícilmente reversible o incluso definitivamente irrecuperable. En estos casos la pérdida de la oportunidad terapéutica atribuible a la Administración sanitaria genera el deber de indemnizar ${ }^{79}$.

En estos casos el daño se configura con la frustración de las expectativas de sanación, por ejemplo, por un error en el diagnóstico de una enfermedad que, de haberse detectado a tiempo, el paciente hubiera tenido posibilidades de curación.

El retraso en el diagnóstico de peritonitis y enfermedades semejantes se ha tratado en Sentencias del Tribunal Supremo, Sala Tercera, de lo Contencioso-Administrativo, de 10 de febrero de 2005 (rec. 1112/2001, FJ $3^{\circ}$ ), 30 de marzo de 2005 (rec. 3184/2001, FJ $2^{\circ}$ ) y 20 de junio de 2006 (rec. 167/2002, FJ $4^{\circ}$ ). Si bien debe mencionarse por su importancia la Sentencia de la misma Sala y Tribunal de 23 de febrero de 2009 (rec. 7840/2004), que se pronuncia sobre la lesión sufrida por un paciente de 45 años de edad, que acude hasta en cuatro ocasiones al hospital con fuertes dolores abdominales, limitándose el servicio de urgencias a recetarle analgésicos. El paciente finalmente sufrió una peritonitis con perforación de la vesícula biliar. El Tribunal Supremo considera en este caso que existe negligencia médica basada en el retraso en el diagnóstico y en la pérdida de oportunidad terapéutica ${ }^{80}$.

78 O. Mir Puigpelat (2008), «Responsabilidad objetiva vs. funcionamiento anormal en la responsabilidad patrimonial de la Administración sanitaria (y no sanitaria)», en S. JiMÉNEz, V. M. Martínez y E. Belda (coords.), Problemas actuales de la responsabilidad patrimonial sanitaria, Madrid: Thomson-Civitas, pág. 163.

79 L. Medina Alcoz (2007), La teoría de la pérdida de oportunidad. Estudio doctrinal y jurisprudencial de derecho de daños público y privado, Cizur Menor: Thomson Reuters-Aranzadi.

80 «Consideramos que, en estas circunstancias, la indebida asistencia sanitaria queda suficientemente acreditada, pues resulta evidente que ese desenlace no es el normal de un 


\section{D) Consentimiento informado}

El paciente que sufre un daño desproporcionado en cuya producción no ha mediado consentimiento informado tiene derecho a ser indemnizado por funcionamiento anormal del servicio sanitario, si bien en este caso debemos descartar cualquier género de presunción de culpa, porque la responsabilidad aflora eminentemente como objetiva: el ordenamiento jurídico exige que se recabe el consentimiento, de manera que su incumplimiento, en presencia de un daño, genera responsabilidad.

Otra cosa es que, aun cuando exista consentimiento informado, incluso en ese caso se infrinja la lex artis, sí que se genere responsabilidad y sea posible presumir la culpa. Por ello sí será compatible el consentimiento informado y la deducción de negligencia, si bien por el funcionamiento anormal del servicio público más allá del consentimiento informado 81 .

Aun cuando el paciente haya prestado su consentimiento, firmando un documento en el que se le informa de los riesgos típicos de la intervención, no por ello la Administración sanitaria se libera de responder. Dicho de otra manera, el consentimiento informado no constituye una cláusula de exoneración de responsabilidad de la Administración, sino que se requiere — para que se determine la ruptura del nexo causalque no se haya infringido la lex artis.

padecimiento como el que aquejaba al recurrente y que le obligó a acudir al servicio de urgencias del hospital administrado por la Generalitat Valenciana en repetidas ocasiones, produciéndose un retraso en el diagnóstico y la consiguiente tardanza en la intervención. La desproporción y la desmesura del resultado, unidas a ese retraso y tardanza, evidencian que hubo una indebida aplicación de la lex artis, por lo que, de acuerdo con la jurisprudencia que hemos sintetizado en el fundamento tercero, correspondía a dicha Comunidad Autónoma acreditar que, por las singularidades del caso, su intervención se ajustó a las prescripciones que esa máxima impone al ejercicio profesional» $\left(\mathrm{FJ} 5^{\circ}\right)$.

81 Así, el Dictamen del Consejo Consultivo del Principado de Asturias 39/2009, de 2 de abril de 2009, informa sobre un caso de fallecimiento de una paciente que había sido intervenida quirúrgicamente en días previos, descubriendo en la autopsia una perforación de colon. El órgano consultivo reproduce el razonamiento de la Sentencia del Tribunal Supremo, Sala Tercera, de lo Contencioso-Administrativo, de 16 de diciembre de 2003 para concluir que el daño es antijurídico en la medida en que «la inicial intervención quirúrgica practicada desencadenó unas consecuencias para la salud de la enferma desmesuradas y que esta no estaba obligada a soportar porque fueron mucho más allá de lo previsible, y tuvieron su origen como destaca el perito en la operación realizada». En consecuencia, en este caso resulta acreditado que el consentimiento informado no impide que se deduzca la negligencia. 


\section{CONCLUSIONES Y RECOMENDACIONES DE LEGE FERENDA}

La presunción de culpa goza de predicamento en nuestro país, pese a los silencios del derecho positivo. Las páginas que anteceden acreditan que los aplicadores del derecho han construido una teoría jurisprudencial y consultiva alrededor de la responsabilidad patrimonial, que en ocasiones pasa desapercibida y hasta se confunde con el carácter objetivo de la responsabilidad.

Hay que insistir en que urge una reconsideración global del régimen de responsabilidad patrimonial, tantas veces demandada, hasta el punto de que las Leyes 39 y 40 de 2015 constituyen una muestra del fracaso del legislador a la hora de atender las instituciones huérfanas de claridad y de seguridad jurídica.

Los vaivenes de la jurisprudencia a la hora de calificar la responsabilidad patrimonial como objetiva o subjetiva, los diferentes criterios, la construcción de esta teoría a golpe de sentencias y resoluciones, todo ello aconseja - con SANTAMARÍA PASTOR- a plantear una reconsideración total del sistema ${ }^{82}$.

Al decir de FERnández Rodríguez, al jurista le compete dar y exigir razones $^{83}$, motivo por el cual al legislador le debemos exigir una regulación unitaria de la responsabilidad patrimonial (su desdoblamiento en las Leyes 39 y 40 de 2015 resulta ciertamente censurable, olvidando la recomendación del Consejo de Estado ${ }^{84}$ ), al tiempo que completa e integradora de todo un corpus jurisprudencial y consultivo amplísimo, en el que algunos aspectos en ocasiones pasan desapercibidos, pese a tener una indudable presencia y una no menor importancia. El instituto de la presunción de culpa es un ejemplo de ello y exige, al igual que el resto de submaterias de la responsabilidad patrimonial, un tratamiento - sin renunciar a la inevitable casuística- al menos claro y unitario.

82 J. A. Santamaría Pastor (2004), prólogo al libro de F. J. DE Ahumada Ramos, La responsabilidad patrimonial de la Administración, Madrid: Thomson Reuters-Aranzadi, 2a ed., págs. 25-35.

83 T. R. FERnÁNDEZ (2001), «Sobre el derecho y el quehacer de los juristas: dar y exigir razones», en F. López Menudo, Derechos y garantías del ciudadano: Estudios en homenaje al profesor Alfonso Pérez, Moreno, Madrid: Iustel, págs. 569-584.

84 Dictamen 275/2015, de 29 de abril de 2015. 
